\title{
Synthesis of graphene quantum dots and their applications in drug delivery
}

\author{
Changhong Zhao ${ }^{1,2^{*}}$, Xuebin Song ${ }^{1}$, Ya Liu ${ }^{2}$, Yifeng Fu ${ }^{2}$, Lilei Ye ${ }^{3}$, Nan Wang ${ }^{3}$, Fan Wang ${ }^{1}$, Lu Li ${ }^{1}$, \\ Mohsen Mohammadniaei ${ }^{4}$, Ming Zhang ${ }^{4}$, Qiqing Zhang ${ }^{1 *}$ and Johan Liu ${ }^{2,5^{*}}$
}

\begin{abstract}
This review focuses on the recent advances in the synthesis of graphene quantum dots (GQDs) and their applications in drug delivery. To give a brief understanding about the preparation of GQDs, recent advances in methods of GQDs synthesis are first presented. Afterwards, various drug delivery-release modes of GQDs-based drug delivery systems such as EPR-pH delivery-release mode, ligand-pH delivery-release mode, EPR-Photothermal delivery-Release mode, and Core/Shell-photothermal/magnetic thermal delivery-release mode are reviewed. Finally, the current challenges and the prospective application of GQDs in drug delivery are discussed.
\end{abstract}

Keywords: Graphene quantum dots, Top-down, Bottom-up, Drug delivery, Delivery-release mode

\section{Introduction}

GQDs are graphene blocks with two-dimensional (2D) transverse size (less than $100 \mathrm{~nm}$ ) [1] and excellent chemical [2], physical [3], and biological properties [4, 5]. An ideal GQD consists of only one atomic layer of carbon atoms. However, most of the synthesized GQDs also contain functional groups like oxygen and hydrogen, and usually have multiple atomic layers with sizes less than $10 \mathrm{~nm}[6]$.

Due to its small size, GQD has a better prospect in biomedical applications than graphene or graphene oxide (GO) [7]. However, prior to designing GQDs into practical applications, their biocompatibility and toxicity are still the main concerns. Studies have shown that GQDs have good biocompatibility [8-10] and low biotoxicity $[11,12]$. Xie et al. [13] studied the cytotoxicity and autophagy induction of three kinds of GQDs, including

\footnotetext{
*Correspondence: 15921061530@163.com; Zhangqiq@126.com; johan. liu@chalmers.se

${ }^{1}$ School of Life Sciences and Technology, Xinxiang Medical University, Xinxiang 453003, P. R. China

2 Electronics Materials and Systems Laboratory, Department

of Microtechnology and Nanoscience, Chalmers University of Technology,

41296 Gothenburg, Sweden

Full list of author information is available at the end of the article
}

cGQDs (HOOC-GQDs), hGQDs (HO-GQDs), aGQDs $\left(\mathrm{H}_{2} \mathrm{~N}-\mathrm{GQDs}\right)$, using lung cancer A549 cells as models. The results showed that hGQDs were the most toxic, leading to significant cell death at $100 \mu \mathrm{g} / \mathrm{mL}$ of hGQD concentration, while cGQDs and aGQDs showed no cytotoxicity within the measured concentration range. Besides cGQDs, aGQDs, and hGQDs can induce autophagy to varying degrees, as shown in Table 1. Further analysis of autophagy pathway showed that all GQDs could significantly activate p-p38MAPK, while p-ERK $1 / 2$ was inhibited by aGQDs and hGQDs but activated by cGQDs. The aGQDs and cGQDs inhibited p-JNK and hGQDs activated p-JNK. On the other hand, Akt was activated by hGQDs, but inhibited by aGQDs. The inhibition of 3-MA on autophagy significantly increased the cytotoxicity of GQDs, suggesting that autophagy has a protective effect on the toxicity of GQDs. The results show that cGQDs have better biocompatibility and more potential in biological applications. Generally, the bioavailability of nanoparticles plays an important role in their safety [14]. However, the amount of cellular uptake showed no significant difference between cGQDs and hGQDs, indicating that bioavailability of GQDs may not explain the difference in toxicity of these GQDs. Although the exact reason is still not clear, the autophagy 
Table 1 Effects of three GQDs on autophagy-inducing related genes

\begin{tabular}{lllll}
\hline & p-p38MAPK & p-ERK1/2 & p-JNK & Akt \\
\hline cGQDs & ++ & + & - & \\
hGQDs & ++ & - & + & + \\
aGQDs & ++ & - & - & - \\
\hline
\end{tabular}

" ++ "indicates significant activation; " + indicates activation; " - indicates inhibition

induction abilities of such GQDs could explain the differences of their toxicity profiles. It was found that cGQDs appears to be even inert in autophagy activation, both aGQDs and hGQDs induced cellular autophagy to various degrees except for cGQDs [13]. Interestingly, hydroxylation was thought to be able to enhance the biocompatibility of nanoparticles [15], but when it comes to GQDs, hGQDs showed the highest toxicity of the three GQDs. Therefore, the influence of surface chemistry on the safety of nanomaterials should not be overgeneralized, and the risk assessment of nanomaterials needs to be handled in a case-by-case manner.

In addition, the monoatomic layer planar conjugate structure, large specific surface area and oxygen-containing functional groups on the surface of GQDs can provide significant active sites and spacious environment to load and carry various drugs/genes/small molecules. Similar with graphene, GQDs have capability to bind with a variety of aromatic bimolecular through the $\pi-\pi$ stacking interaction and/or electrostatic binding. However compared with graphene sheets, GQDs exhibit improved biocompatibility and minimal toxicity [16-18], making them more promising materials for delivering of biologically active cargoes into living systems. In recent years, many researchers have been dedicated to the application of GQDs in drug delivery systems [19-21]. Although, study in this field is still in its primary development period, a comprehensive review article focusing on the applications of GQDs in drug delivery is highly demanded.

In this review, we outline the recent advancements in synthesizing of GQDs together with an analysis and comparison study on their pros and cons and suitable applications. Moreover, the applications of GQDs in drug delivery are summarized and discussed, while various GQDs based drug delivery-release modes are reviewed and compared.

\section{Synthesis methods of GQDs}

The existing methods for GQDs synthesis can be generally divided into top-down and bottom-up processes (Fig. 1) [22]. As the bottom-up methods, synthesis of
GQDs requires complex reaction steps and specific organic materials, making it difficult to optimize the conditions. Therefore, it is preferred to use the topdown approach, which is to cut large blocks of carbon materials into small pieces. The raw materials needed for this method are abundant carbon materials, which are cheap and easy to obtain, also the method is relatively straightforward and easy to synthesize GQDs.

\section{Top-down strategy}

There are many methods for GQDs synthesis based on top-down processes, including chemical oxidation method [24-26], hydrothermal method [27, 28], ultrasonic assisted method [29], electrochemical oxidation method [30], chemical vapor deposition (CVD) method [31-33], and pulsed laser ablation (PLA) technique [34-37], or a combination of the above different approaches [38].

\section{Chemical oxidation method}

Chemical oxidation method, also known as oxidation cutting method, is a very widely used method, in which carbon bonds of graphene, $\mathrm{GO}$ or carbon nanotubes are usually destroyed by $\mathrm{H}_{2} \mathrm{SO}_{4}, \mathrm{HNO}_{3}$ or other oxidants [39-43].

Liu et al. [44] developed an experimental system, which used Vulcan XC-72 carbon black as carbon source and strong oxidant concentrated nitric acid reflux to prepare high purity GQDs. The yield and purity of GQDs were $75 \mathrm{wt} \%$ and $99.96 \mathrm{wt} \%$ respectively. At different excitation wavelengths, the prepared GQDs exhibited multicolor photoluminescence (PL) from green to red (Fig. 2).

In order to avoid the use of concentrated acids and the introduction of metal impurities, Lu et al. [45] synthesized GQDs with black carbon as precursor and hydrogen peroxide $\left(\mathrm{H}_{2} \mathrm{O}_{2}\right)$ as the oxidant in a pot of hydrothermal method without any additional post-treatment steps. The diameter of synthesized GQDs was 3.0$4.5 \mathrm{~nm}$. The whole synthesis process takes only $90 \mathrm{~min}$, and has good light stability, salt tolerance, low toxicity and good biocompatibility. Compared with many other reported methods, it is a more green and faster method for GQDs synthesis. After that, Halder et al. [46] also used GO as the precursor, oxidized and cracked it in $2 \mathrm{~h}$ with the help of $\mathrm{H}_{2} \mathrm{O}_{2}$, to obtain GQDs products, which also did not need further purification steps.

Due to the use of strong oxidants such as $\mathrm{H}_{2} \mathrm{SO}_{4}$ and $\mathrm{HNO}_{3}$, the chemical oxidation method is not very safe, and the generated chemical waste is liable to pollute the environment. 


\section{Top-down}
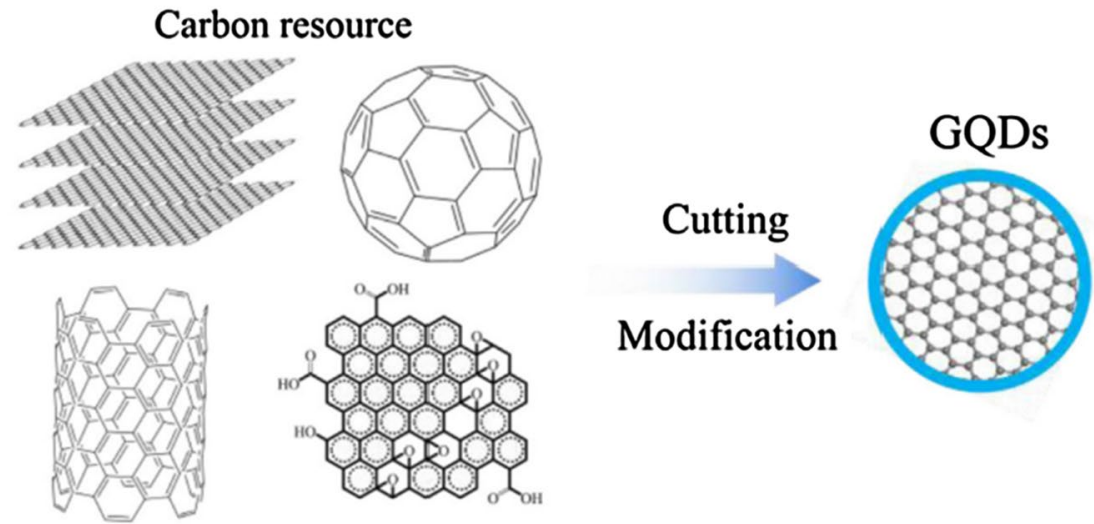

\section{Bottom-up}

\section{Small molecules}
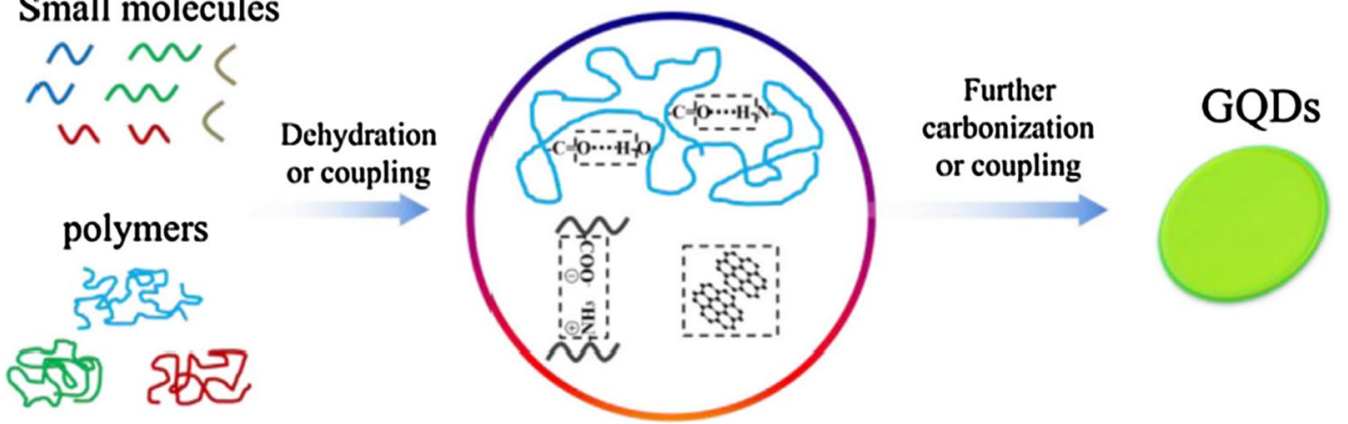

Fig. 1 Two main approaches were adopted to prepare fluorescent GQDs: the "top-down"splitting route from different carbon sources and "bottom-up" method from small molecules or polymers (reprinted/reproduced with the permission of Ref. [23], copyright 2017, Nano Today)
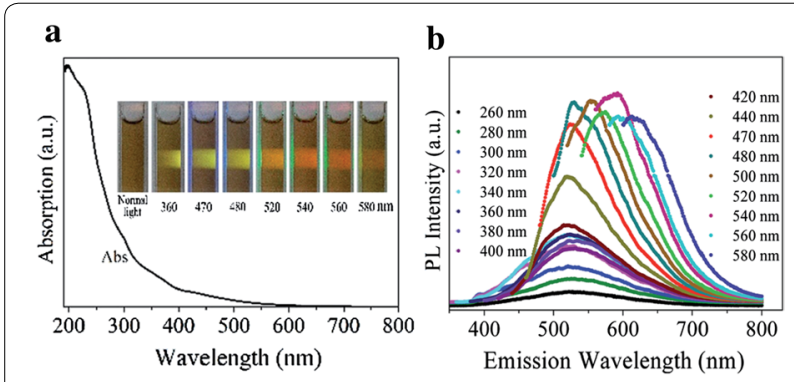

Fig. 2 a UV-vis absorption spectrum of the GQDs at different excitation wavelengths. Inset: optical photograph of the GQDs dispersed in water under different wavelengths of irradiation. $\mathbf{b} \mathrm{PL}$ spectra of the GQDs at excitation wavelengths from 260 to $580 \mathrm{~nm}$ (reprinted/reproduced with the permission of Ref. [44], copyright 2015, RSC Advances)

\section{Hydrothermal method}

Hydrothermal method is a simple and rapid method for preparing GQDs [47-50]. GQDs can be finally obtained using a variety of macromolecular or small molecular substances [51] as the starting materials through high temperature and pressure [52-55]. The principle is to break the bonds between carbon materials to form GQDs via high temperature under high pressure [56-59].

Tian et al. [60] used $\mathrm{H}_{2} \mathrm{O}_{2}$ to synthesize GQDs in N, $N$-dimethylformamide (DMF) environment by one-step solvothermal method. In the whole preparation process, the use of concentrated sulfuric acid and nitric acid to treat raw materials was completely avoided, whereas no impurities were introduced (Fig. 3). High purity GQDs could be obtained by evaporation/re-dissolution and filtration without dialysis. The results showed that the diameter and thickness of GQDs were mainly distributed within the range of $20-40 \mathrm{~nm}$ and $1-1.5 \mathrm{~nm}$, respectively. Under neutral conditions, the quantum yield (QY) was $15 \%$. The PL signal represented a good stability under different $\mathrm{pH}$ conditions, which indicates that it has broad application prospects in different environments. This method has many advantages such as low cost, high quantum yield, no requirement for dialysis and purification, simple experimental setup, etc. The prepared GQDs 


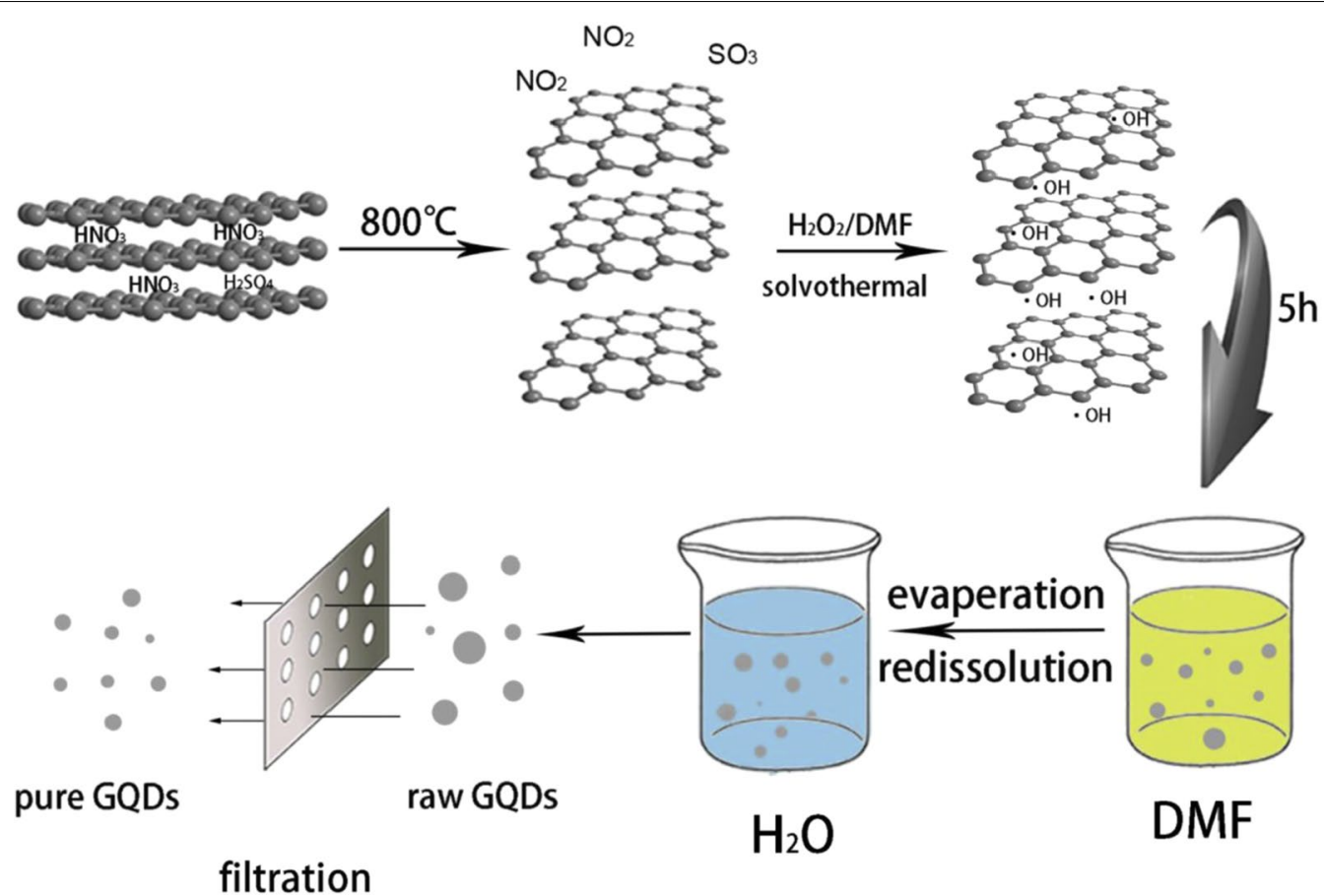

Fig. 3 Schematic representation of GQDs prepared by solvothermal method (reprinted/reproduced with the permission of Ref. [60], copyright 2016, Optical Materials)

were environmentally friendly and displayed sound water solubility to represent their promising applications in the field of biomedical and bioelectronic devices.

Recently, Zhang et al. [61] successfully synthesized reduced graphene oxide quantum dots (rGOQDs) in $5 \mathrm{~h}$. They used graphite as the starting material to prepare GO by an improved Hummers' method, and then GO and DMF were utilized as the raw materials for further hydrothermal treatment in a poly(tetrafluoroethylene) (Teflon)-lined autoclave at $200{ }^{\circ} \mathrm{C}$. The QY of the synthesized rGOQDs was $24.62 \%$, and the surface doping was nitrogen $(\mathrm{N})$ extracted from DMF. They also studied zebrafish by rGOQDs, which provided valuable reference for the biocompatibility of bio-probes in vivo.

In order to make full use of crop biomass, some researchers [62] used rice husk as the raw material to produce high-quality GQDs by hydrothermal method. The mass fraction of QY is about $15 \mathrm{wt} \%$. The prepared GQDs showed good colloidal stability in water with bright and adjustable PL signals. Experiments suggested that, the synthesized GQDs has good biocompatibility and can be easily translocated into cytoplasm, to be used for cell imaging. In addition, mesoporous silica nanoparticles (MSNs) as the by-products were synthesized during the synthesis of GQDs.

Hydrothermal method can be used to dope many elements or groups, and the raw materials come from a wide range of composites [63]. Moreover, the hydrothermal method can be combined with chemical oxidation method to prepare different GQDs [64-66]. However, it suffers from the safety issue, because of the high temperature and pressure, and also it generally takes a long time, usually at least $5 \mathrm{~h}[67,68]$.

\section{Ultrasound assisted method}

Ultrasonic technology is also a common method for material synthesis $[69,70]$. Under the action of ultrasound, tens of thousands of small bubbles will be formed in the liquid, and the mechanical force generated can destroy the carbon-carbon bonds, thus cutting into GQDs (Fig. 4).

Gao et al. [71] prepared three kinds of GQDs of pristine graphene quantum dots (PGQDs), expanded graphene quantum dots (EGQDs) and graphene oxide quantum dots (GOQDs) using natural graphite, expanded graphite, and oxide graphite as the raw materials in a supercritical $\mathrm{CO}_{2} / \mathrm{H}_{2} \mathrm{O}$ system assisted by ultrasound. The experimental results show that this method is an environmentally friendly, low-cost, fast and large-scale synthesis method of GQDs, which it can provide an alternative green route for the production of various GQDs, especially PGQDs.

Balaji et al. [72] calcined the latex of Calotropis gigantea to $300{ }^{\circ} \mathrm{C}$ and extracted it with ethanol. The pure rGOQDs can be obtained by re-dispersing the 


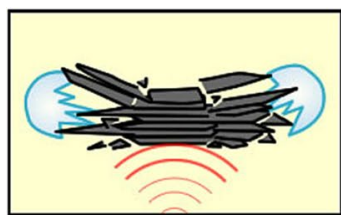

pristine graphite

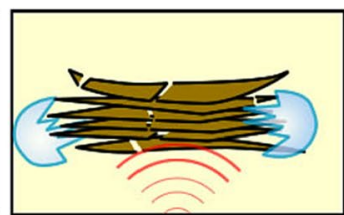

expanded graphite

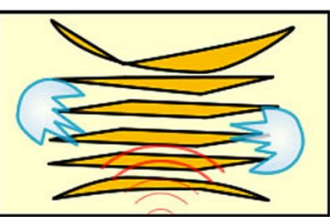

graphite oxide

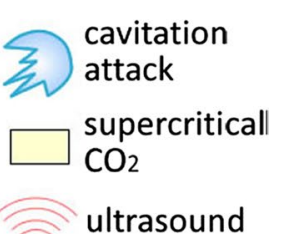

ultrasound

Fig. 4 Illustration of the exfoliation process of pristine graphite, expanded graphite and graphite oxide in ultrasonic-assisted scCO 2 process (reprinted/reproduced with the permission of Ref. [71], copyright 2017, Ultrasonics Sonochemistry)

extract in Milli-Q water with a 15 min sonicate treatment and further centrifuging at $5000 \mathrm{rpm}$. The particle size of rGOQDs ranged from 2-8 $\mathrm{nm}$ and showed green fluorescence in the long ultraviolet range of 360-520 $\mathrm{nm}$. It can be used to design more environmentally friendly and economical $\mathrm{Pb}^{2+}$ fluorescent probes, since, it provides a simple and suitable method for the selective and sensitive detection of $\mathrm{Pb}^{2+}$ in water purification process. In addition, the rGOQDs were also prepared for free radical scavenging and bioimaging applications. They showed the advantages of stability, cost-effectiveness, good biocompatibility and environmental protection to play an important role in the field of nanotechnology-based biomedicine in the near future. Although, combination of hydrothermal and ultrasound-assisted methods have shown to improve their drawbacks in the fabrication of GQDs $[73,74]$.

\section{Electrochemical oxidation method}

In the electrochemical oxidation method process, carbon-carbon bonds of graphite, graphene, or carbon nanotubes are oxidized and decomposed into GQDs at a high redox voltage $(+1.5$ to $+3 \mathrm{~V})[30,75]$.

In order to controllably and efficiently prepare highly crystalline GQDs in aqueous systems, researchers [76] have developed a weak electrolyte (such as ammonia solution) electrochemical method to enhance the oxidation and cutting process, thereby achieving high yield of GQDs. The af-GQDs were prepared using a circular graphene paper as the anode, a Pt sheet as the cathode, and an ammonia solution (nitrogen source) as the electrolyte and operated in a constant voltage mode $(30 \mathrm{~V})$ for $2 \mathrm{~h}$ in an electrochemical cell (Fig. 5). GQDs had a size of 3-8 $\mathrm{nm}$ and QY of $28 \%$, which was approximately 28 times greater than that of the strong electrolytes (such as borax solution). At the same time, GQDs also showed significantly better crystallinity than the bottom-up GQDs. In addition, the amino

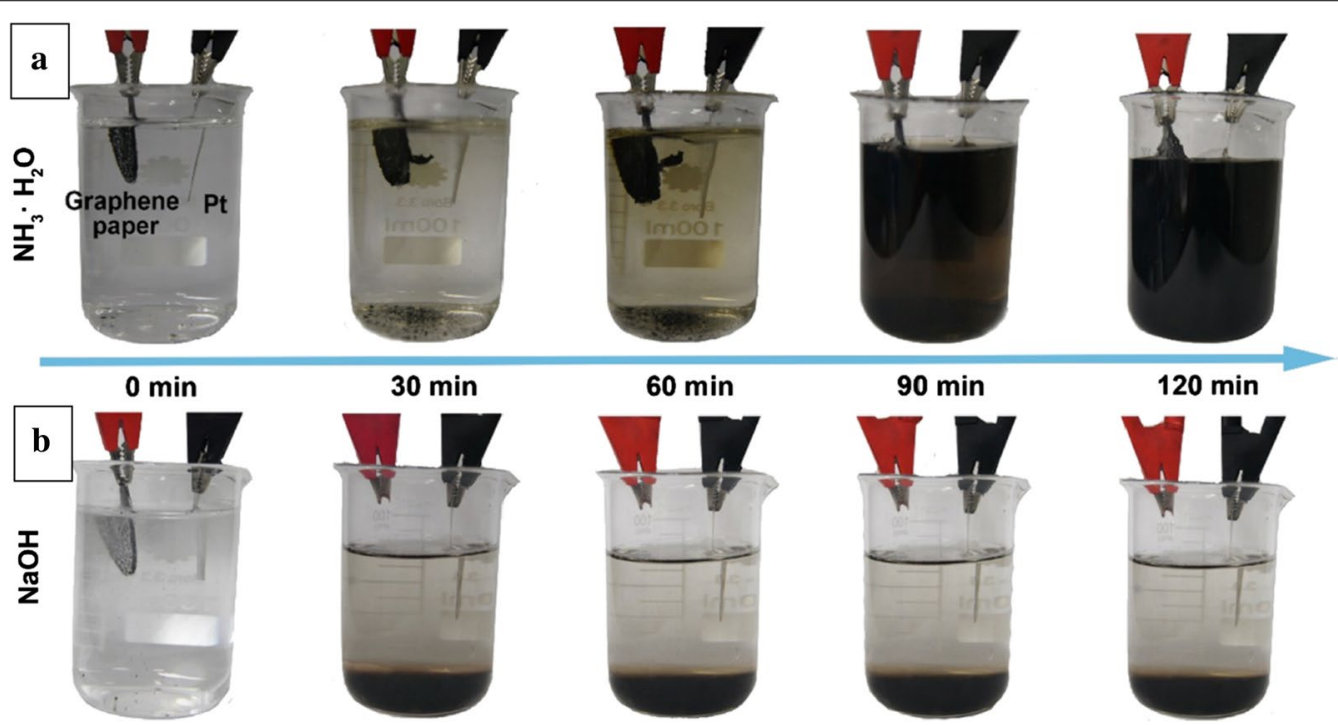

Fig. 5 The electrolytic process of graphene paper in $\mathbf{a}$ ammonia and $\mathbf{b} \mathrm{NaOH}$ solutions under different reaction times (reprinted/reproduced with the permission of Ref. [76], copyright 2018, Langmuir) 
functionalization of GQDs can be controlled by controlling the electrolyte concentration. In addition, this method can also be used in other weak electrolytes (such as $\mathrm{HF}$ and $\mathrm{H}_{2} \mathrm{~S}$ ) and anode precursors (such as graphene/graphite paper, carbon fiber and carbon nanotubes) to prepare other types of GQDs.

In a study conducted by by Chen et al. boron-doped graphene quantum dots (BGQDs) were synthesized by potentiostatic electrolysis [75]. Firstly, they put high purity graphite rod (carbon source) as the anode and PT sheet as the cathode into borax solution (boron source) of $\mathrm{pH} \approx 7$. Oxidization and decomposition of graphite at high redox voltage $(3 \mathrm{~V})$ for $2 \mathrm{~h}$ led to the production of BGQDs. Then, a $0.22 \mu \mathrm{m}$ microporous nylon membrane filtration and dialysis bag (retained molecular weight of $3500 \mathrm{Da}$ ) were used to obtain a high-purity BGQDs solution.

The GQDs solution prepared by the electrochemical oxidation method has high stability, but the pretreatment of raw materials and the purification of GQDs products take a long time, and the QY is relatively low, which makes it difficult to achieve large-scale production of GQDs.

\section{Other methods}

Due to the unique structure and excellent properties of GQDs, researchers have reported more and more preparation methods based on the popular techniques, such as chemical vapor deposition (CVD) $[33,77]$ and pulsed laser ablation (PLA) $[78,79]$.

For example, Deka et al. [31] prepared a PL sensor based on hydrophobic graphene quantum dots (h-GQDs) using acetylene and hydrogen as raw materials by CVD, which can distinguish aromatic and non-aromatic amino acids (Fig. 6). They first grew graphene on the $\mathrm{Cu}$ substrate through a custom CVD system, then transferred it directly to $n$-hexane which was followed by obtaining $\mathrm{h}-\mathrm{GQDs}$ after $8 \mathrm{~h}$ of ultrasonic treatment. This is the first report on the direct synthesis of CVD-assisted h-GQDs, which can form highly stable dispersions in organic solvents without functionalization, doping or binding with other molecules.

In order to open up a new way to prepare GQDs, Kang et al. [34] prepared GQDs from multi-walled carbon nanotubes (MWCNTs) by PLA. They first dispersed MWCNTs as carbon precursors in n-hexane and ethanol, respectively. Ultrasound treatment was then carried out in the solution for $2 \mathrm{~h}$ to achieve uniform dispersion of MWCNT (Fig. 7). GQDs were

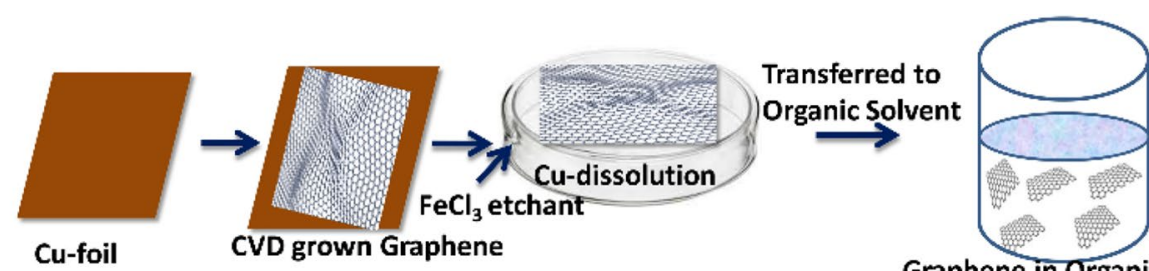

Graphene in Organic solvent
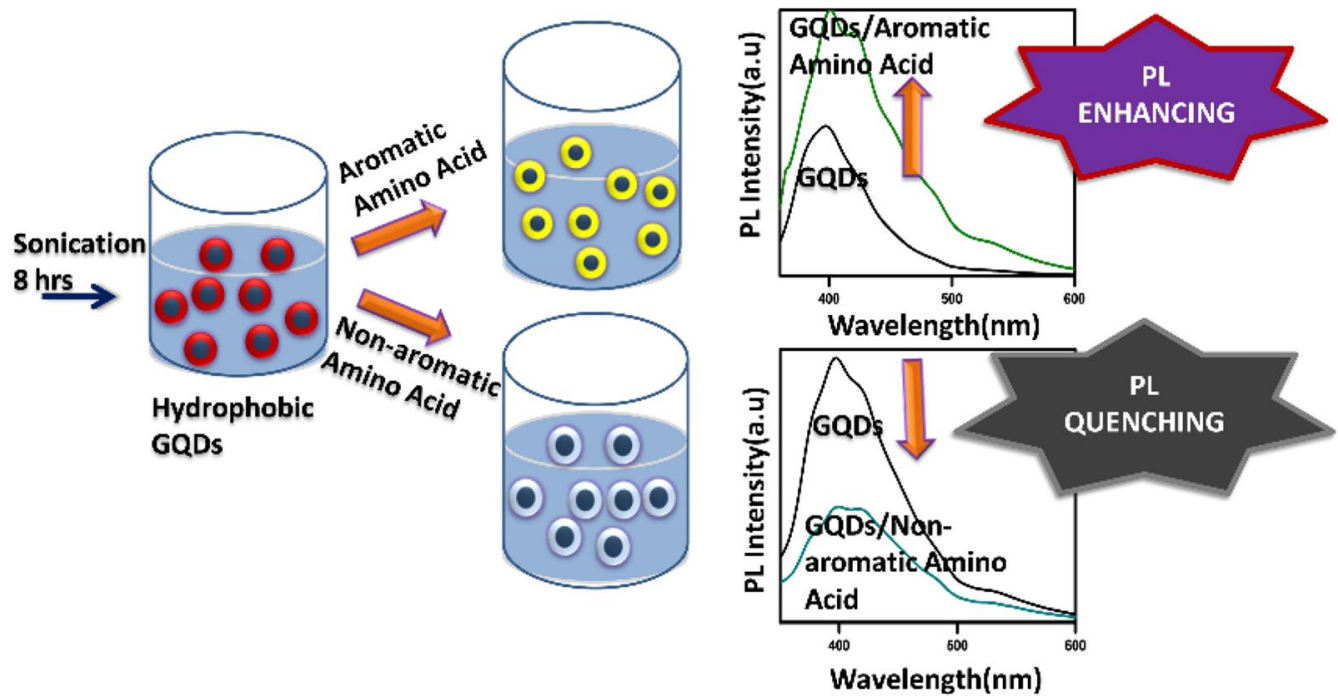

Fig. 6 Schematic representation of the strategy employed to synthesize h-GQDs and fabrication it as a sensing system which can distinguish between aromatic and non-aromatic amino acids (reprinted/reproduced with the permission of Ref. [31], copyright 2017, ChemistrySelect) 

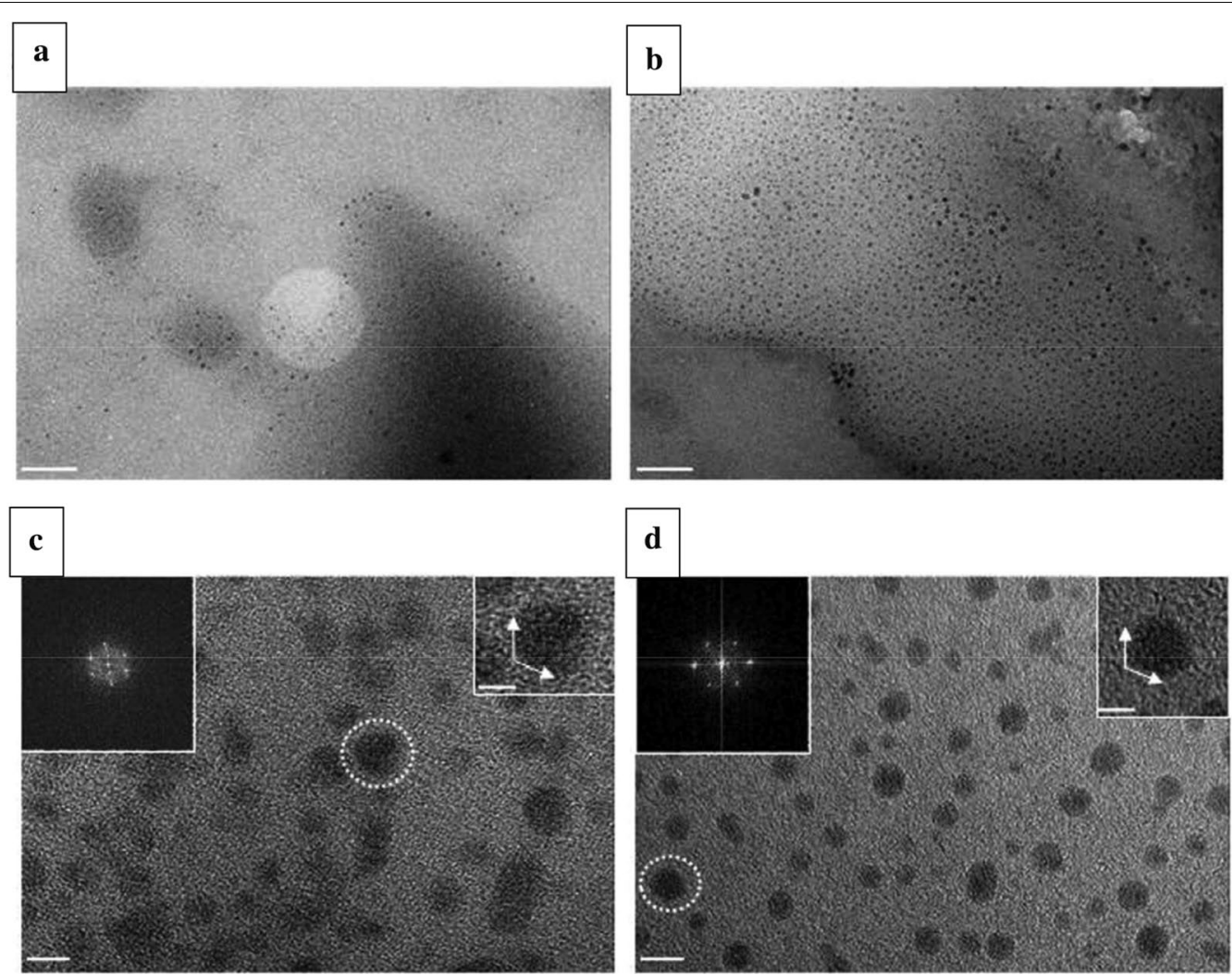

Fig. 7 HR-TEM images of e-GOQDs and h-GQDs. a TEM image of e-GOQDs and $\mathbf{b}$ h-GQDs. They both showing the uniform round shape and size distribution of $1 \sim 5 \mathrm{~nm}$. Scale bar $50 \mathrm{~nm}$. c HRTEM image of e-GOQDs and $\mathbf{d}$ h-GQDs. Insets are the 2D FFT patterns (left). They both show high quality crystalline hexagonal patterns of these quantum dots. Scale Bar $5 \mathrm{~nm}$. Right side insets show the edge structure of e-GOQDs and h-GQDs. Scale bar $2 \mathrm{~nm}$ (reprinted/reproduced with the permission of Ref. [34], copyright 2016, Scientific Reports)

fabricated rapidly by transferring $50 \mathrm{~mL}$ solution to glass bottle and then using a 6 min pulsed laser peeling (PLE) process on a fixed bottle. The synthesized GQDs represented an obvious blue PL with the QY of $12 \%$, and showed sufficient brightness and resolution, to make them suitable for photoelectric applications.

In addition, some researchers [80-84] have prepared GQDs by other methods, but it has not been widely used due to their disadvantages such as difficult particle size control, low yield, long reaction time and complex process.

\section{Bottom-up strategy}

The bottom-up approach generally includes microwave method [73, 85-87], molecular carbonization [88-90], and electron beam irradiation (EBI) methods [91, 92]. Generally, small molecules [93, 94] such as citric acid (CA) [95-97], amino acid [98, 99], phenyl compounds [91, 100-103], or small molecule sugar [104-106] are used as the starting material.

\section{Microwave method}

The long reaction time of hydrothermal method is a common problem, so microwave technology has become a fast heating method, which is widely used in the preparation of nanomaterials [107-109]. It not only shortened the reaction time, but also increased the yield.

Zhang et al. [110] used aspartic acid (Asp) and $\mathrm{NH}_{4} \mathrm{HCO}_{3}$ as raw materials, DI water as solvent, purified GQDs by microwave irradiation for $10 \mathrm{~min}$ and dialysis membrane for $7 \mathrm{~h}$ (Fig. 8). The prepared GQDs showed strong blue fluorescence and QY of 14\%. The strong fluorescence quenching effect of $\mathrm{Fe}^{3+}$ on GQDs can be used for highly selective detection in general metal ions. GQDs is also sensitive to $\mathrm{pH}$ value (2-12), which shows that it has great potential for optical $\mathrm{pH}$ sensors. In addition, GQDs can be directly used as fluorescent probe for cell imaging due to its low cytotoxicity and high photostability.

In order to obtain GQDs with good biocompatibility, sensing and in vivo bioimaging capabilities, Campbell et al. [111] used glucosamine- $\mathrm{HCl}$ solution as a carbon 


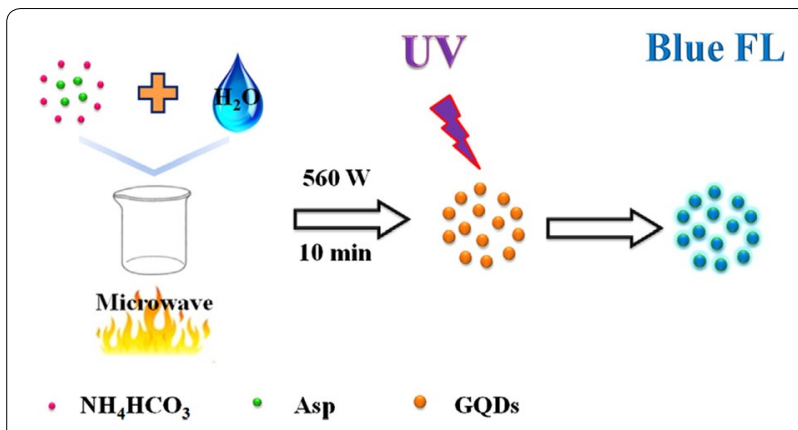

Fig. 8 Schematic illustration of the preparation process for the GQDS (reprinted/reproduced with the permission of Ref. [110], copyright 2016, Talanta)

source and added different dopant precursors (sulfur thiourea or benezeneboronic acid) to synthesize various GQDs, including N-GQDs, NS-GQDs, and BN-GQDs. After the mixed solution was subjected to microwave treatment for $40 \mathrm{~min}$, it was treated with dialysis membranes for 7 days, and GQDs with QY of $15-20 \%$ were obtained. After examining the cytotoxicity and $\mathrm{pH}$ fluorescence response of the prepared GQDs, it was found that they have a great potential in drug delivery, $\mathrm{pH}$-sensing of cancerous environments, and multicolor visible/ near-infrared (NIR) fluorescence imaging.

The microwave method greatly shortens the time for synthesizing GQDs, which can be obtained in a few minutes, and can be doped with various elements, which enriches the types of GQDs and expands the functions of GQDs.

\section{Molecular carbonization method}

The preparation of GQDs by molecular carbonization is an environmentally friendly and simple method [90, 112]. Its principle is to use suitable organic molecules or polymers for dehydration and further carbonization [113-115].

Bayat et al. [116] synthesized low cost and high yield green photoluminescent single-layer graphene quantum dots (SLGQDs) using DI water as solvent and glucose as precursor. The synthesized SLGQDs were uniformly dispersed without obvious aggregation, and their average size was about $8 \mathrm{~nm}$. The maximum emission wavelength was about $540 \mathrm{~nm}$. The formation mechanism of SLGQDs was as follows (Fig. 9). First, dehydration of glucose molecule to form $\mathrm{C}=\mathrm{C}$ and basic unit of graphene structure through hydrothermal reaction; second, interaction of hydrogen atoms of glucose molecule with hydroxyl group of adjacent glucose molecule to form water molecule; finally, covalent interaction of carbon atom to form GQDs. The prepared SLGQDs have the advantages of low cost, high yield and large scale.

In another report, Teymourinia et al. [117] prepared GQDs with corn flour as green precursor. The diameter of synthesized GQDs was $20-30 \mathrm{~nm}$. Broad emission centered at $450 \mathrm{~nm}$ was observed in the emission spectrum (PL) of $360 \mathrm{~nm}$ excitation wavelength. The

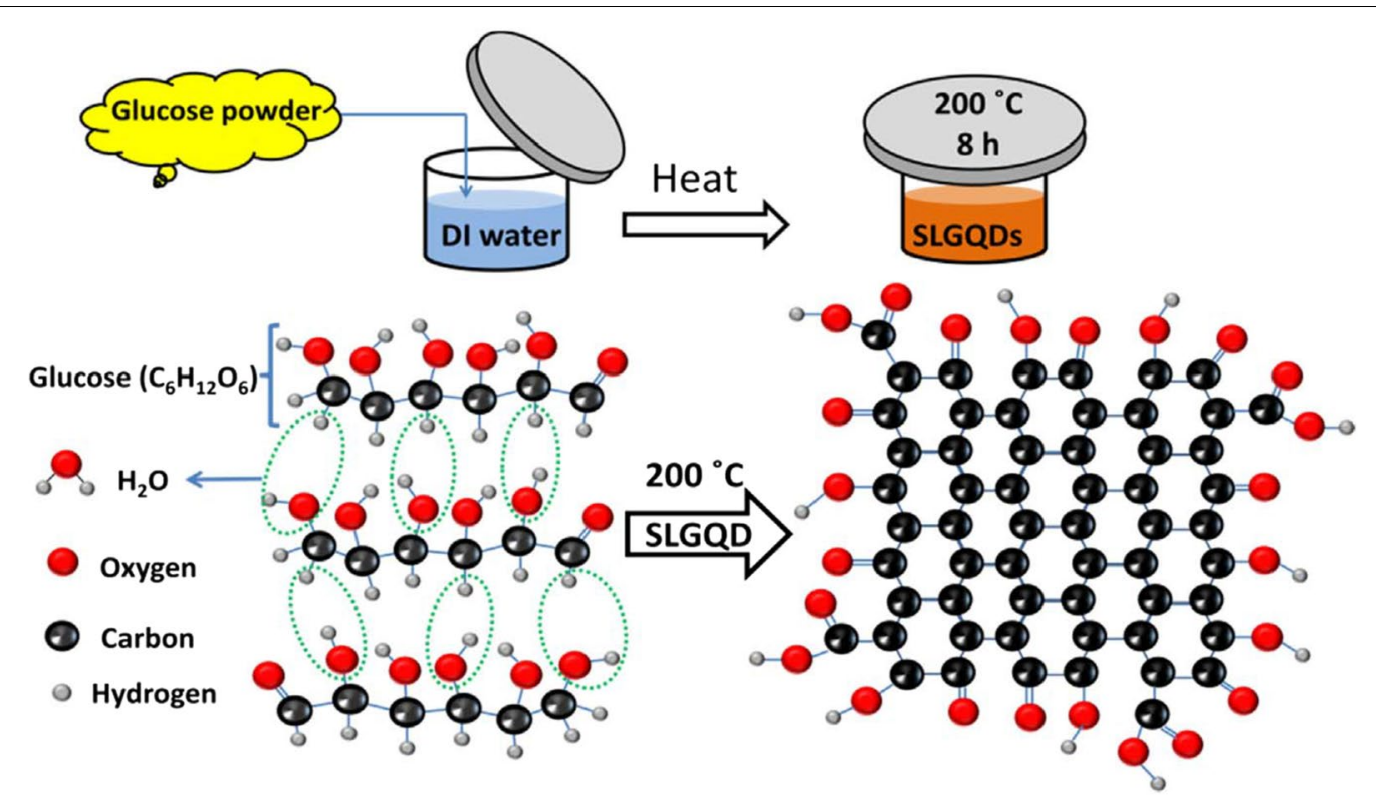

Fig. 9 Formation mechanism of the SLGQDs via a hydrothermal method at $200^{\circ} \mathrm{C}$ for $8 \mathrm{~h}$ (reprinted/reproduced with the permission of Ref. [116], copyright 2017, Journal of Luminescence) 
excitation spectrum (PLE) showed a broad peak centered at $365 \mathrm{~nm}$.

The application of molecular carbonization method is relatively challenging. Since the size and structure of GQDs cannot be accurately controlled, the GQDs obtained using this method is multi-dispersive [118-120].

\section{Electron beam irradiation (EBI) method}

It is worth to note that, the EBI method [121] requires expensive professional equipment and has the risk of being injured by radiation, so it has not been widely used. Wang et al. [122] synthesized single crystal fluorescent GQDs by EBI at room temperature. 1,3,6-trinitropyrene was dissolved in a solution of hydrazine hydrate. Then, it was sealed in a plastic bag after stirring, and irradiated under the titanium window of a dynamitron electron accelerator (Fig. 10). After irradiation, the sample was dialyzed through a $0.22 \mathrm{~mm}$ microporous membrane filter and a dialysis bag for $2 \mathrm{~d}$, and finally a GQDs with $32 \%$ QY was obtained. Other small molecules such as 1-Nitropyrene, urea, and CA can also be used as precursors to synthesize GQDs at the same conditions.

Generally, GQDs are prepared by cutting carbon materials, including graphene, fullerene and carbon nanotubes, through top-down strategies, including chemical oxidation method, hydrothermal method, ultrasound Assisted method, electrochemical oxidation method, CVD method, and PLA method, or using appropriate organic molecules or polymers as raw materials. Bottomup strategies include microwave method, molecular carbonization method, and EBI method. Generally, small molecules such as CA, amino acids, phenyl compounds or small molecular sugars are used as starting materials, or different elements are doped to synthesize GQDs with multiple functions. Table 2 summarizes the advantages and disadvantages of different methods.

In all GQDs preparation methods, hydrothermal methods are often combined with chemical oxidation methods to break down large molecules such as graphite, fullerene, $\mathrm{C}_{60}$, carbon nanotubes, and even crop biomass. The sources of raw materials are very rich, so they are widely used. The microwave method has the advantages of short reaction time, simple operation, cheap equipment, and no pretreatment of raw materials, so researchers can quickly prepare GQDs for further experiments.

\section{Applications of GQDs in drug delivery}

In recent years, the applications of GQDs in drug delivery [123-127], sensors [128-134], bio-imaging [10, 63, 135-140], magnetic hyperthermia [141-143], photothermal therapy [144-148], antibacterial [145, 149, 150], catalyst [69, 151-155], environmental protection [38, 156, 157], and energy [158-163] has made remarkable accomplishment. In order to better apply GQDs to drug delivery, some researchers had used density functional theory (DFT) calculations [164-167], molecular dynamics (MD) simulations $[168,169]$, or other methods $[170,171]$ to theoretically study the properties of GQDs. For example, Vatanparast et al. [166] studied the interaction of 5-fluorouracil (FU) with undoped/doped GQDs by DFT calculations. The results showed that AlN and AlP doped GQDs could serve as potential carriers for FU drugs in the nanomedicine domain. Later, they [167] used DFT calculations to study the applications of GQDs and doped GQDs as potential carriers of isoniazid (Iso). The results confirmed that the AlN- and AlP-doped GQDs could be used as potential carriers for drug delivery applications. Recently, they [169] also has studied the effects of different $\mathrm{N}$-functionalities groups in the drug delivery performance of N-GQDs via DFT calculations and MD simulations. The drug release performance of the center $\mathrm{N}$-GQDs is considered to be superior to that of pristine GQDs and edge N-GQDs. This review focuses on the research accomplishment of GQDs in drug delivery.

There are many ways of drug delivery, but simply focusing on drug delivery and ignoring drug release cannot improve the therapeutic effect of drugs. Therefore, more and more researchers have being paying attention to the close relationship between drug delivery and drug release and try to develop a variety of drug delivery-release mode, in order to improve the therapeutic effect of drugs by improving drug delivery and release efficiency.

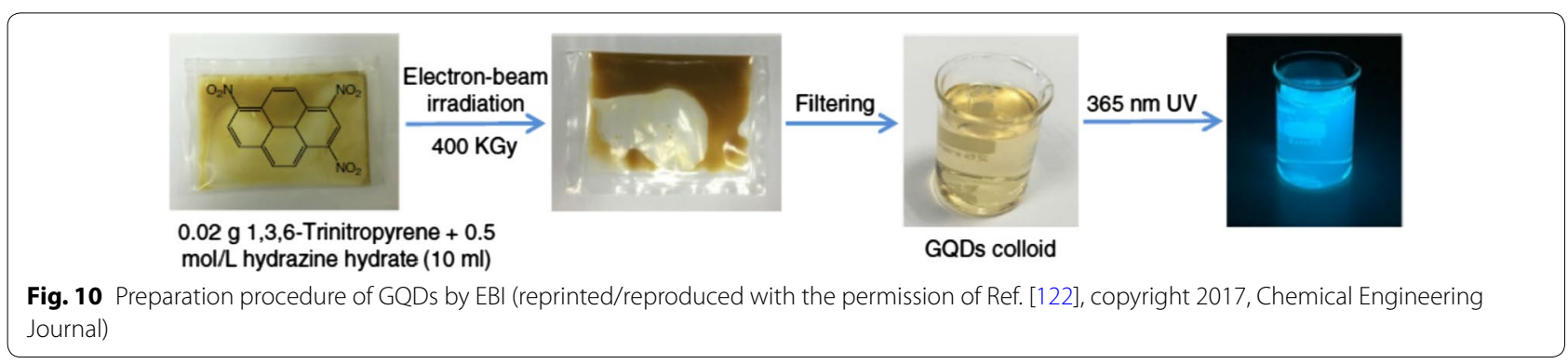


Table 2 Advantages and disadvantages of different methods

\begin{tabular}{|c|c|c|c|}
\hline & Methods & Advantages & Disadvantages \\
\hline \multirow[t]{5}{*}{ Top-down strategy } & Chemical oxidation Method & $\begin{array}{l}\text { It is widely used method at present; it is } \\
\text { simple and effective and can be used in } \\
\text { large-scale production }\end{array}$ & $\begin{array}{l}\text { It usually needs to use } \mathrm{H}_{2} \mathrm{SO}_{4}, \mathrm{HNO}_{3} \text { or other } \\
\text { oxidants, which may cause corrosion or } \\
\text { explosions }\end{array}$ \\
\hline & Hydrothermal/solvothermal method & It is a green, simple and fast method & $\begin{array}{l}\text { Reaction time is long; some raw materi- } \\
\text { als need to be treated by strong oxidant } \\
\text { before reaction occurs; reaction also } \\
\text { involves high temperature and high } \\
\text { pressure, which may cause combustion or } \\
\text { explosion }\end{array}$ \\
\hline & Ultrasound assisted method & $\begin{array}{l}\text { It can shorten the reaction time and } \\
\text { improve the yield }\end{array}$ & $\begin{array}{l}\text { It is difficult to synthesize on a large scale in } \\
\text { industry }\end{array}$ \\
\hline & Electrochemical Oxidation Method & $\begin{array}{l}\text { The GQDs produced are stable and uniform } \\
\text { in size distribution }\end{array}$ & $\begin{array}{l}\text { The pretreatment of raw materials and the } \\
\text { yield of products is low, so it is difficult to } \\
\text { carry out large-scale production }\end{array}$ \\
\hline & Other method & & $\begin{array}{l}\text { It is difficult particle size control, low yield, } \\
\text { long reaction time and complex process }\end{array}$ \\
\hline \multirow[t]{3}{*}{ Bottom-up strategy } & Microwave method & $\begin{array}{l}\text { It greatly shortens the reaction time and } \\
\text { is green }\end{array}$ & $\begin{array}{l}\text { It is difficult to carry out large-scale produc- } \\
\text { tion and requires filtration and purification }\end{array}$ \\
\hline & Molecular carbonization method & $\begin{array}{l}\text { It is an environmentally friendly and simple } \\
\text { method }\end{array}$ & $\begin{array}{l}\text { It is impossible to control the size and } \\
\text { structure of GQDs accurately; the obtained } \\
\text { GQDs are multi-dispersive }\end{array}$ \\
\hline & Electron beam irradiation method & It is simple, fast and high yield & $\begin{array}{l}\text { It requires expensive professional equipment } \\
\text { and has the risk of being injured by radia- } \\
\text { tion, so it has not been widely used }\end{array}$ \\
\hline
\end{tabular}

GQDs is a novel and efficient nano-material for biological therapy. Graphene or graphene-based nanomaterials $[145,172]$ have been reported for drug delivery and release in order to improve delivery efficiency and enhance therapeutic effects [143, 171-174]. Compared with graphene, GQDs have better water solubility, lower cytotoxicity $[61,150,175,176]$, and larger specific surface area, which makes them more effective drug molecular loading cores [12, 177, 178].

As a member of graphene family and carbon-based nanomaterials, GQDs have a number of advantages over other nanoparticles in the application of drug delivery due to their low toxicity, large surface/volume ratio and their massive capabilities of surface functionalization. When compared to other traditional nanoplatforms, such as polyethylene glycol (PEG), GQDs may provide more bonding sites for chemotherapeutic conjugation and improved cell uptake ability [179]. Compared with quantum dots (QDs) of similar size, GQDs exhibit superior properties such as quantum confinement effects, ability for simultaneous tracking due to their tunable photoluminescence (PL) but relatively lower toxicity due to the lack of heavy metal components [180]. Therefore, GQDs have great potential for biomedical application. Moreover, owing to their planar structure, GQDs possess a large surface area to volume ratio, which allows for higher efficiency of drug loading and delivery [142]. Furthermore, the unique $\pi$-orbitals in the sp2-hybridized GQD lattice can be used to bond drugs containing an aromatic ring structure through $\pi-\pi$ stacking, without covalent conjugation, which widens the application of GQDs for drug delivery.

A schematic diagram showing the drug delivery and release in GQDs based system is shown in Fig. 11 [181]. First, the drugs are delivered to the target cells by EPR effect or the targeting ligand, then up taken by cells. Similar with other non-degradable nanoparticle drug carriers, drugs released from GQDs via a diffusion process. For example, the adsorbed drugs on GQDs can be released into cytoplasm by desorption and diffusion.

GQDs were proved to be able to across the bloodbrain barrier (BBB) and prevent $\alpha$-synucleinopathy in Parkinson's disease without surface functionalization [182]. Generally, size and charge of the nanoparticles have important influence on their $\mathrm{BBB}$ permeation. Smaller nanoparticles are able to cross the BBB more easily and to diffuse better through the brain. For example, gold nanoparticles under $15 \mathrm{~nm}$ were found to be able to cross the BBB without any functionalization. However, gold nanoparticles bigger than $50 \mathrm{~nm}$ were failed to across BBB and not found in the brain [183]. Similarly, the small size is considered to the main reason why GQDs can across BBB, and GQDs across biological barriers probably through the transmembrane or the paracellular pathway. 


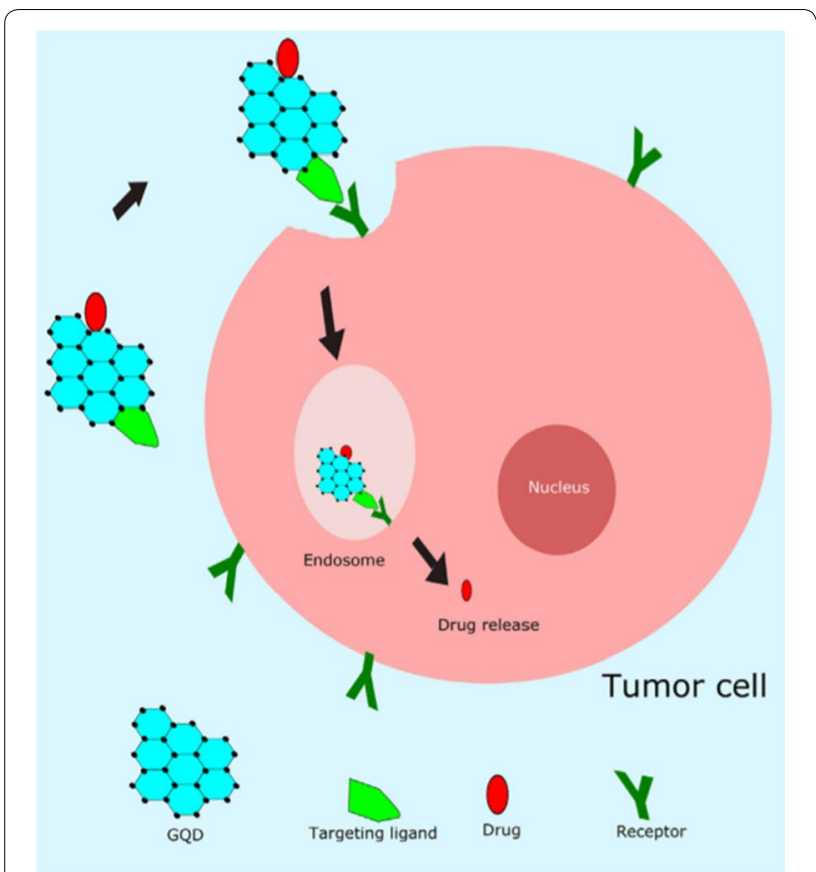

Fig. 11 Illustration of receptor-mediated endocytosis of targeting ligand-conjugated GQDs loaded with an anticancer drug into a tumor cell and drug release inside the cell (reprinted/reproduced with the permission of Ref. [181], (reprinted/reproduced with the permission of Ref. [181], copyright 2020, Materials Science \& Engineering: $\mathrm{C}$ )

The integration of cancer diagnosis and treatment has been always a concern for the biomedical researchers. Although considerable progress has been made in targeting drug delivery systems to deliver anticancer drugs to specific sites of interest, new nanomaterials are often developed and explored for better drug delivery efficiency. While developing new nanomaterials, new drug delivery-release modes have also been explored. Generally, there are enhanced permeability and retention (EPR)-pH delivery-release mode [184], ligand-pH delivery-release mode $[99,185,186]$, EPR-Photothermal Delivery-Release Mode [123], and Core/Shell-photother$\mathrm{mal} /$ magnetic thermal delivery-release mode $[187,188]$. In addition, other delivery-release modes are generally used to treat non-tumor diseases.

\section{EPR-pH delivery-release mode}

Drug-Loaded Delivery-Release System (DDRS) can be used to deliver drugs to tumor sites through the EPR effect and released in low $\mathrm{pH}$ microenvironments for anti-tumor chemotherapy.

In a report by Khodadadei et al. [184], blue fluorescent nitrogen-doped graphene quantum dots (N-GQDs) were synthesized by hydrothermal method using $\mathrm{CA}$ as the carbon source and urea as the nitrogen source. N-GQDs were loaded with methotrexate (MTX) through $\pi-\pi$ superposition interactions, thereby preparing MTX- $(\mathrm{N}-$ GQDs) DDRS (Fig. 12). The release of MTX in vivo was simulated by the release of MTX-(N-GQDs) in phosphate buffered saline (PBS) at $\mathrm{pH}$ 7.4. In vitro cytotoxicity tests on human breast cancer cells (MCF-7) showed that $\mathrm{N}-$ GQDs were well compatible with cells, while MTX-(NGQDs) had higher cytotoxicity and longer culture time than MTX alone Inside. This study confirms the progress of GQDs as nanocarriers in prolonging the cytotoxicity of drug-loaded cells, thereby better killing cancer cells.

To overcome the hypoxia-induced resistance to chemotherapy in the tumor microenvironment, Wei et al. [189] established a DDRS based on Pt and polyethylene glycol-GQDs. First, GQDs were synthesized by chemical oxidation of dried CX-7 carbon black with $\mathrm{HNO}_{3}$. Subsequently, $\mathrm{ClCH}_{2} \mathrm{COH}$ hydroxylated GQDs- $\mathrm{COOH}$ supported cisplatin via a covalent bond. Further, PtGQDs-COOH was obtained. Finally, polyethylene glycol (PEG) was connected to Pt-GQDs-COOH by stirring to synthesize a polyethylene glycol-graphene quantum dotPt (GPt) with a diameter of about $5 \mathrm{~nm}$ (Fig. 13). Oral squamous cell carcinoma (OSCC) and BALB/cJNJuFoxn $1^{\mathrm{nu}} / \mathrm{Nju}$ (4 weeks old) xenograft tumor male mice were used to detect GPt in vitro and in vivo, respectively. It was found that GPt has a good therapeutic effect on OSCC under both normoxic and hypoxic conditions. Compared with free cisplatin, after GPt enters mice through the tail vein, GPt has a stronger inhibitory effect on tumor growth, and systemic drug toxicity is not obvious. This is mainly because GPt is easier to enter tumor tissues through the EPR effect, and releases Pt for antitumor in an acidic environment. Potential new strategies for the preparation of GPt for therapy targeting the tumor microenvironment.

In general, when the function of DDRS is usually relatively simple, in this EPR-pH delivery-release mode, the drug may be released early during delivery, and the efficacy will be reduced due to the lower penetration performance. To improve tissue permeability and cell uptake, Ding et al. [41] developed a new type of anticancer drug with excellent therapeutic properties. Firstly, GQDs were prepared from polyacrylonitrile carbon fibers by simple chemical oxidation and exfoliation. DOX is then loaded on the surface of GQDs via $\pi-\pi$ interaction to obtain DOX@GQDs. GQDs were coupled with Cy5.5 (Cy) dye, a NIR fluorescent molecule, via a cathepsin D-responsive (P) peptide, and finally DOX@GQDs-P-Cy was synthesized. DOX@GQDs-P-Cy was evaluated in vitro and in vivo by $4 \mathrm{~T} 1$ breast cancer cells, 3D multicellular tumor spheroid (MCTS) model, and tumor-bearing mice, respectively (Fig. 14). It was found that GQDs-PCy has good biocompatibility. After loading DOX, it is 


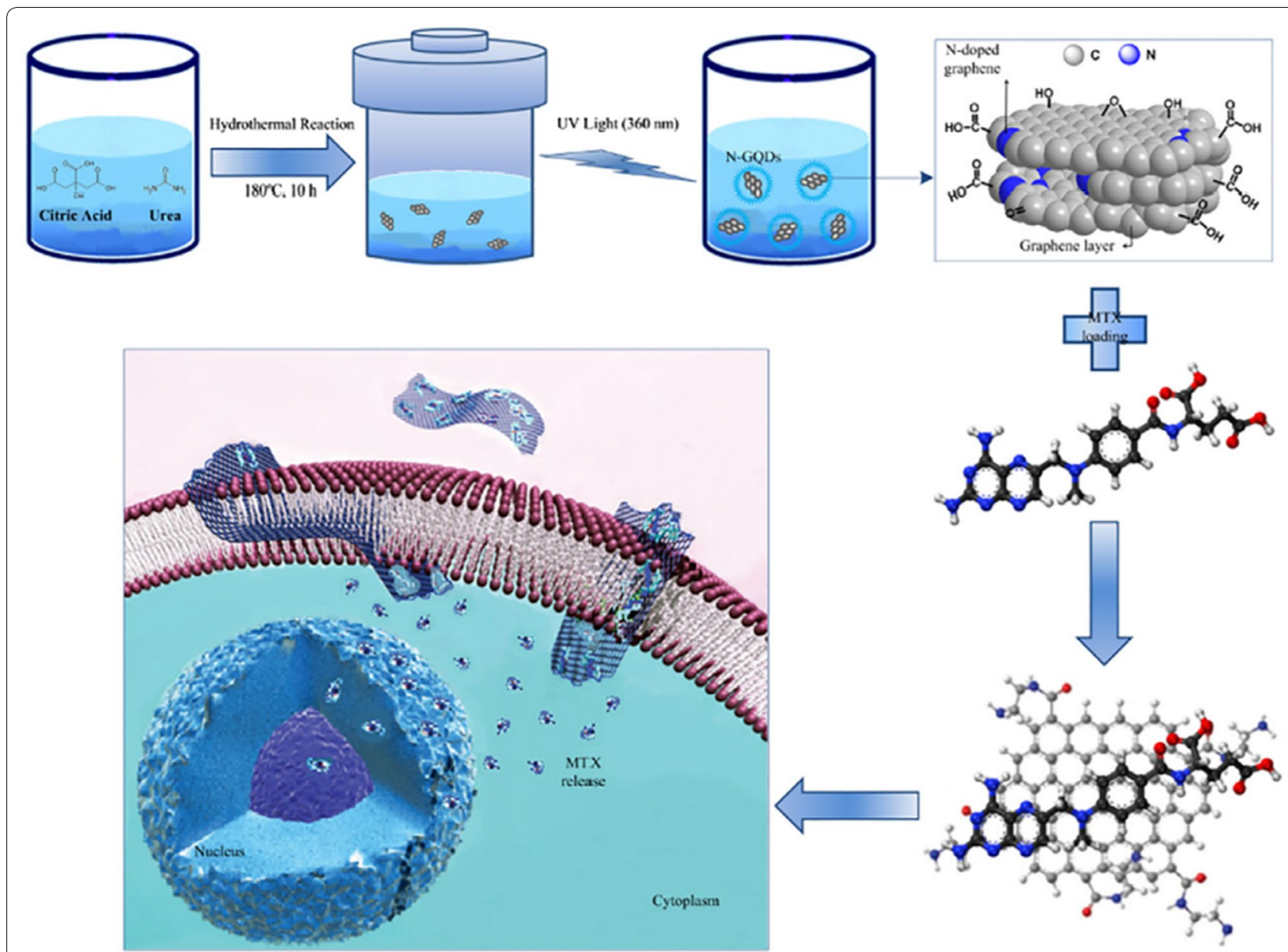

Fig. 12 Preparation of N-GQDs and subsequent release of MTX from the surface of N-GQDs in a tumor cell environment (reprinted/reproduced with the permission of Ref. [184], (reprinted/reproduced with the permission of Ref. [184], copyright 2017, Materials Science and Engineering: C)

significantly more cytotoxic than free DOX, and DOX@ GQDs-P-Cy has stronger tumor penetration ability. DOX@GQDs-P-Cy is injected intravenously into tumorbearing mice. Compared with free DOX, tumor uptake of DDRS is more favorable for tumors. The tumors shrink faster, and tumor-bearing mice survive longer. In addition, the DOX@GQDs-P-Cy can also be used as a probe to trace the delivery process and release site of anticancer drugs. The negative correlation between the fluorescence intensity of the NIR fluorescence signal of Cy triggered by cathepsin D and the relative speed of tumor growth can also be used to accurately assess the apoptosis in chemotherapy in real time. This versatile DDRS that monitors drug delivery, release, and treatment will help establish personalized anti-cancer therapies.

\section{Ligand-pH delivery-release mode}

Generally, to achieve accurate anti-tumor treatment, first, the antitumor drugs are loaded on DDRS through $\pi-\pi$ interactions. Then, tumor is targeted by the
DDRS-loaded drugs through ligand-receptor interactions. Finally, antitumor drugs are released from DDRS in the low $\mathrm{pH}$ environment of tumor cells for effective tumor ablation [190].

Iannazzo et al. [191] established a good biocompatible and cell-traceable drug delivery system based on GQDs for inserting the doxorubicin (DOX) drug into DNA for delivery to cancer cells (Fig. 15). They first synthesized highly dispersed water-soluble GQDs by chemical oxidation using MWCNTs as raw materials. In order to be able to effectively recognize biotin receptors that are overexpressed in cancer cells, they are covalently linked to the tumor targeting module biotin (BTN) and loaded with DOX through $\pi-\pi$ interactions to obtain GQDsBTN-DOX delivery-release system. In vitro cytotoxicity tests using A549 cells showed that the synthesized GQDs and GQDs-BTN had no significant toxicity. In A549 cells treated with GQDs-BTN-DOX, cytotoxicity is closely related to cellular uptake. After treatment with GQDsBTN-DOX, cell uptake was larger and delayed compared 


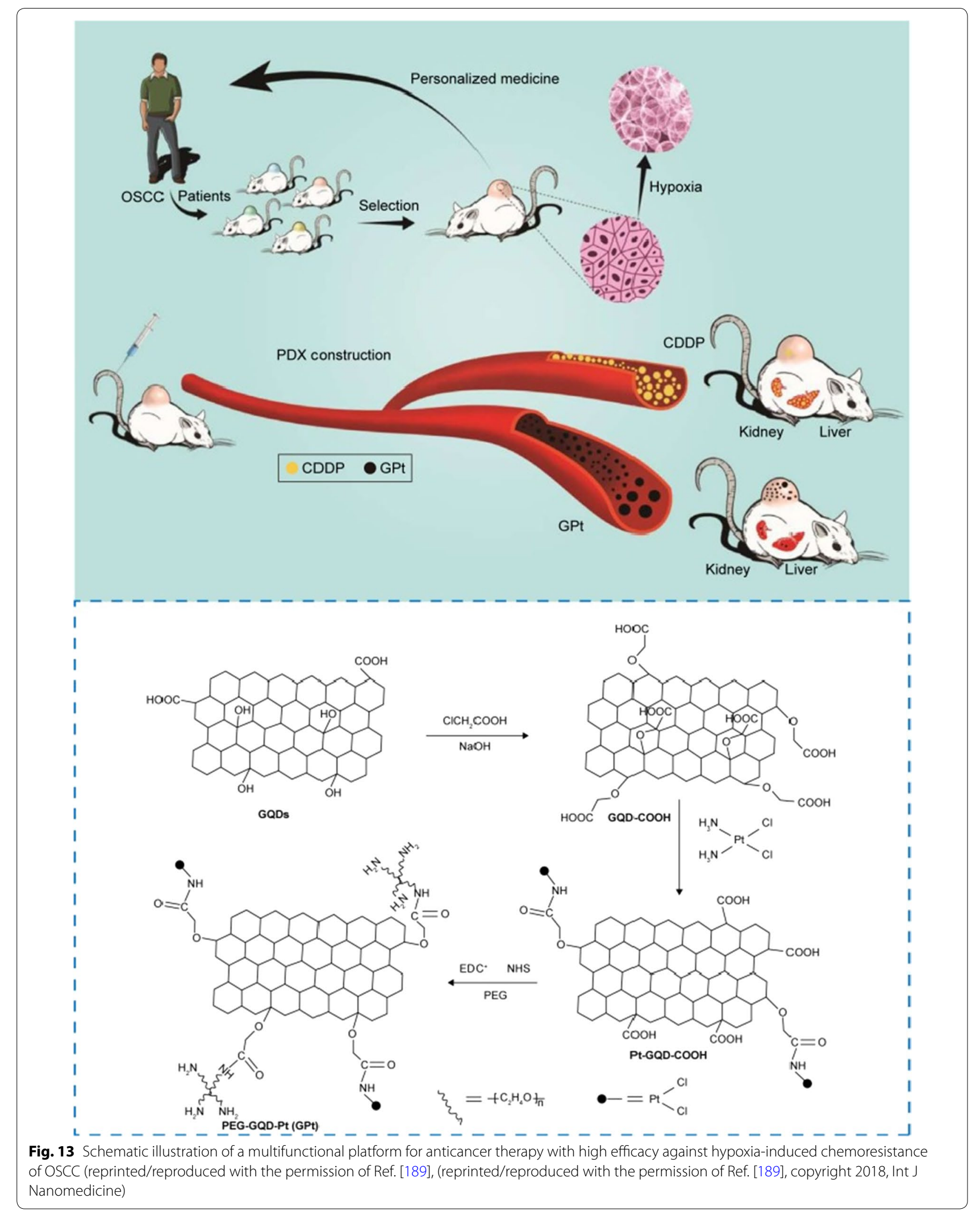




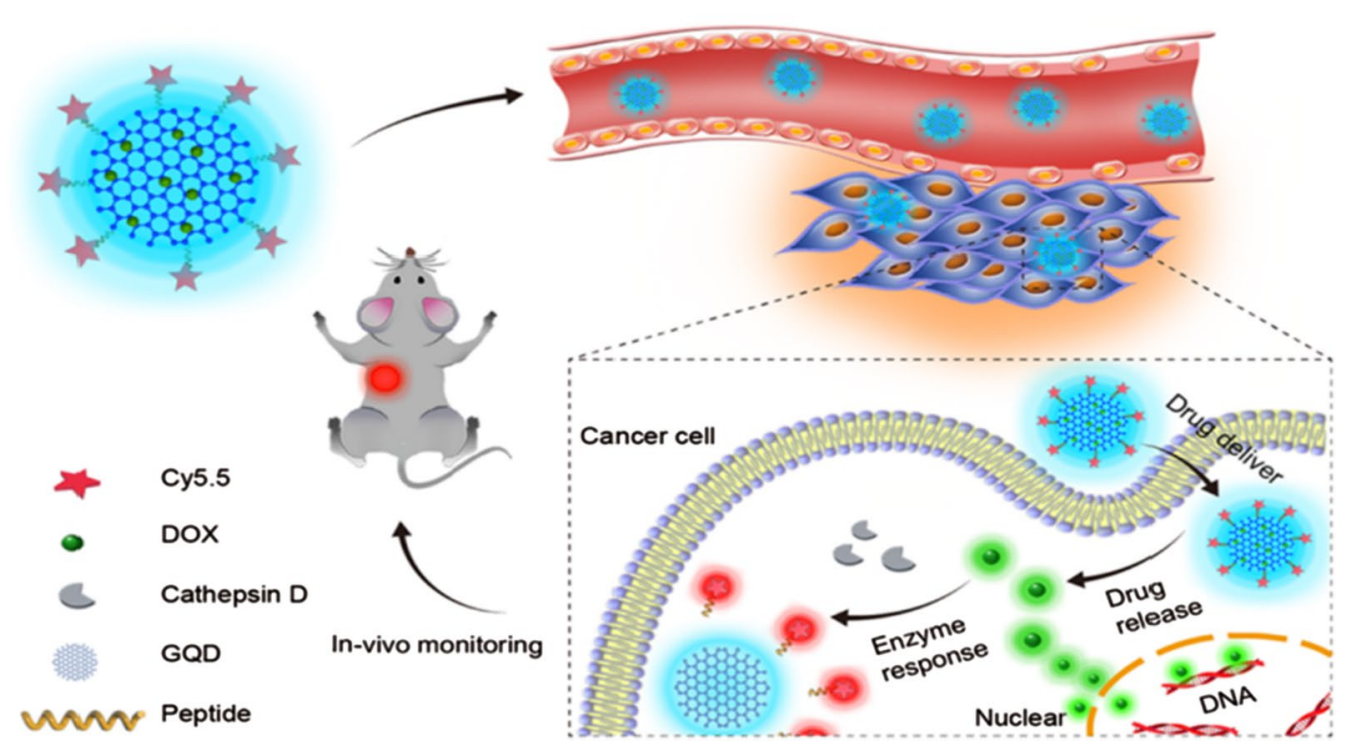

Fig. 14 Strategy of GQDs-based theranostic agent for programmatically monitoring anticancer drug delivery, release, and response (reprinted/ reproduced with the permission of Ref. [41], copyright 2017, ACS Applied Materials \& Interfaces)

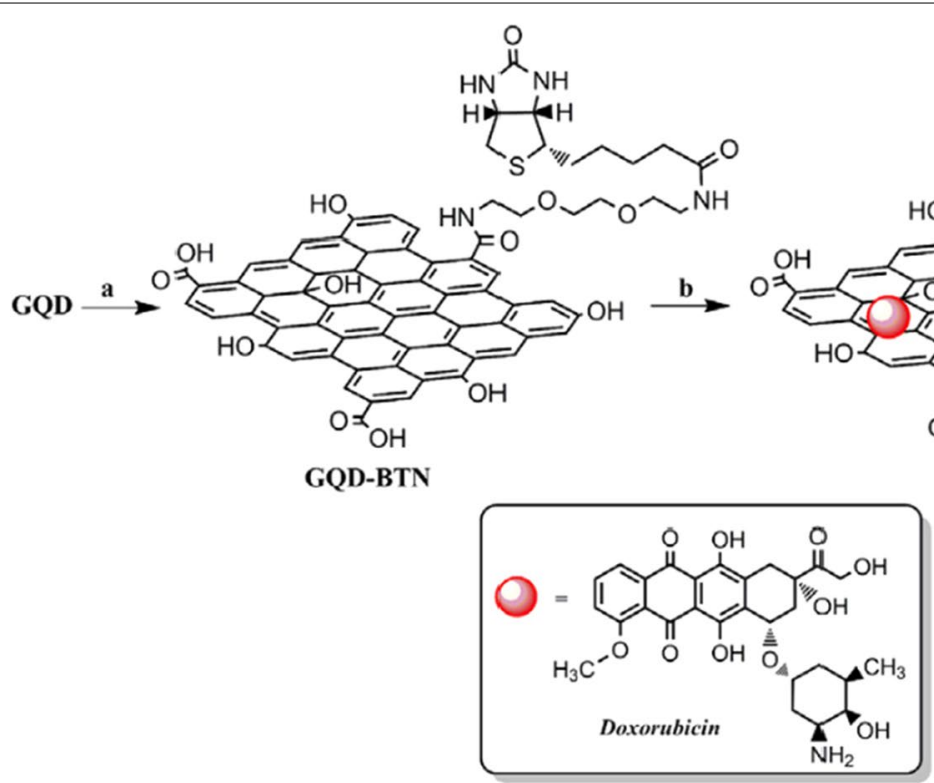

Fig. 15 Synthesis of GQDs-BTN-DOX. Reagents and conditions: a BTN, EDC.HCl, HOBt, DMAP, $\mathrm{CH}_{2} \mathrm{Cl}_{2}, 4 \mathrm{~d}$, r.t.; b DOX, buffer solution pH 7.4, 24 h, r.t (reprinted/reproduced with the permission of Ref. [191], copyright 2017, Int J Pharm)

to cell uptake observed with GQDs-DOX or free DOX. The drug delayed nuclear internalization because the acidic environment of cancer cells caused the drug to detach from the system. In addition, intrinsic fluorescence enables tracking of drug release.

Based on the previous experience, they [192] have prepared similar intelligent DDRS, which also has drug loading and targeting functions. First, GQDs and PEG are assembled to form GQDs-PEG-BFG, which has the function of supporting anticancer drugs with a benzofuran structure (BFG). Then, using pyrene as a linker, it was linked to the targeting ligand riboflavin (RF, vitamin B2) through a $\pi-\pi$ interaction. The GQDs-PEG-BFG@ Pyr-RF (Fig. 16) was formed to target cancer cells. Functions. Biological tests were performed on synthetic DDRS using three cancer cell lines, laryngeal cancer cell line 


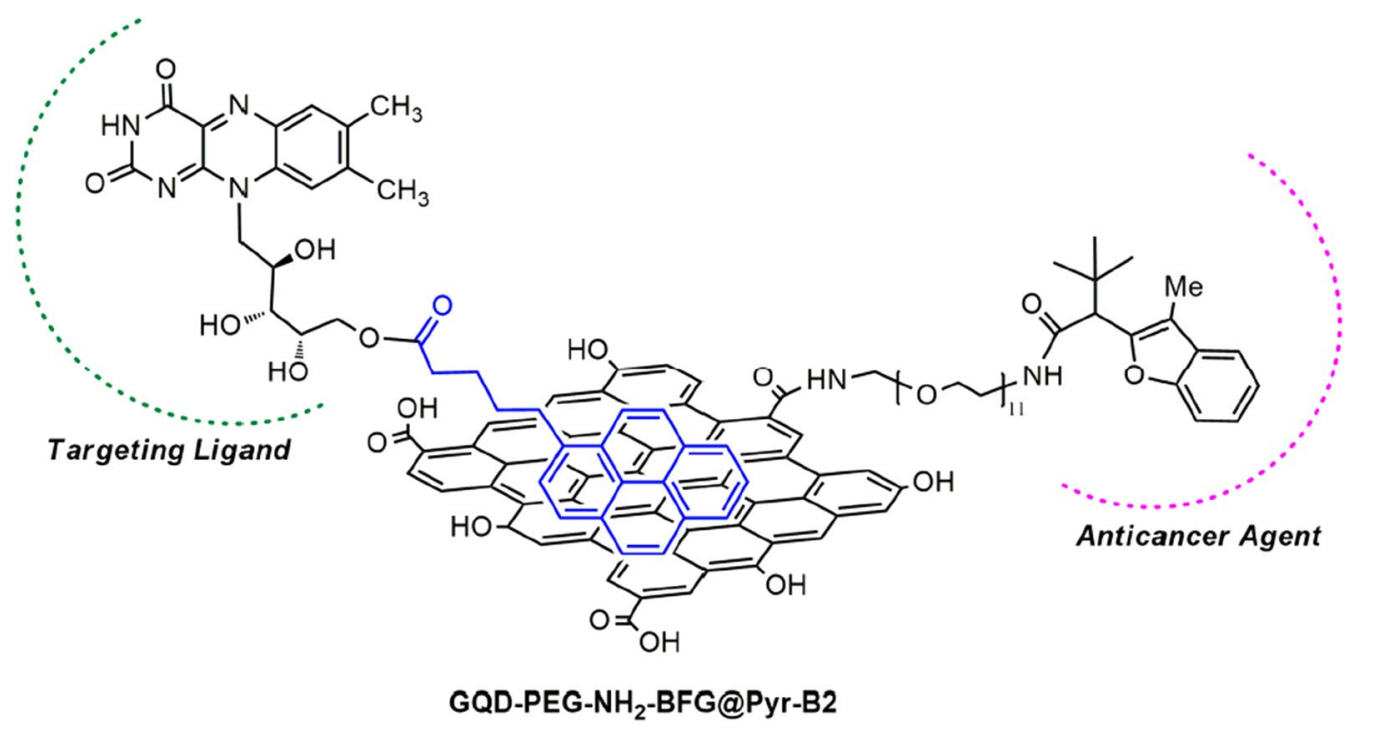

Fig. 16 Cancer targeted DDRS based on GQDs (reprinted/reproduced with the permission of Ref. [192], copyright 2019, Nanomaterials)

(HEp-2), human lung epithelial cancer cell line (A549), and human colorectal adenocarcinoma cell line (HT-29). GQDs-PEG-BFG@Pyr-RF, GQD-PEG-BFG, and GQDs@ Pyr-RF were found to be low cytotoxic, but toxic to cancer cells, compared to free BFG. This new DDRS provides new ideas for the application of anticancer drugs with poor water solubility, low cell uptake, systemic toxicity and adverse side effects. It also shows that GQDs, a new generation member of the graphene family, have shown broad application prospects in anticancer treatment.

Qin et al. [193] developed a new nano-scale DDRS based on GQDs, only 9-12 nm, for the treatment of ovarian cancer. First, GQDs were synthesized by hydrothermal method using graphite as a raw material. Subsequently, the targeting ligand folic acid (FA) was coupled to GQDs, giving GQDs the ability to target cancer cells. Next, the chemotherapeutic DOX is loaded on it via $\pi-\pi$ stacking interaction to form the final DDRS, GQDsFA-DOX, which was somewhat similar to the design by Wang et al. [194] (Fig. 17). The performance of GQDsFA-DOX was tested using the normal ovarian epithelial cell line T80 and the ovarian carcinoma cell line OVCAR3. It was found that the synthesized DDRS had no toxic effect on normal ovarian cells and had ideal therapeutic effects on ovarian cancer cells. GQDs-FA-DOX provides a novel and effective strategy for targeted therapy of ovarian cancer.

In addition, in order to deliver pancreatic cancer-specific drugs in rats, Joshi et al. [195] synthesized a novel DDRS (Fig. 18) based on silver-graphene quantum dot (Ag-GQDs) nanocomposites. First, glutamine was used as the raw material, and pure GQDs were obtained after

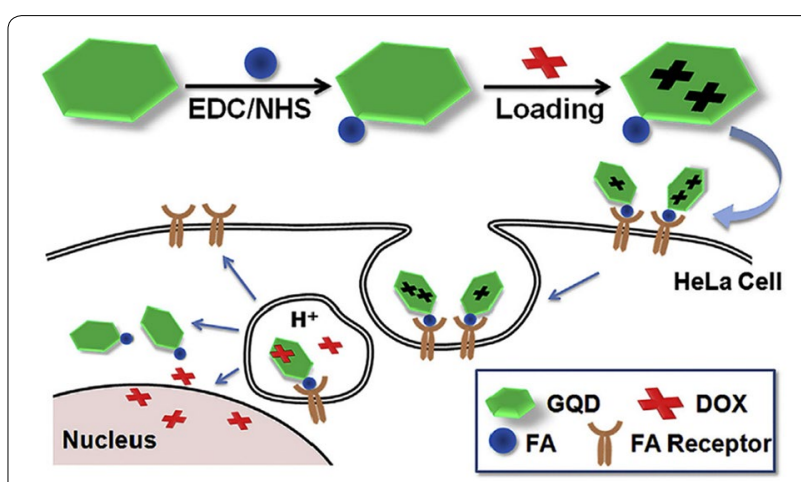

Fig. 17 Schematic of the fabricated DOX-GQDs-FA nanoassembly for DOX deliveryinto target cells (reprinted/reproduced with the permission of Ref. [194], copyright 2014, Colloids and Surfaces B: Biointerfaces)

high-temperature cracking at $190-200{ }^{\circ} \mathrm{C}$ and further high-speed centrifugation to remove impurities. Subsequently, GQDs and a certain amount of $\mathrm{AgNO}_{3}$ solution were mixed, and $\mathrm{Ag}^{+}$was reduced in situ using tri sodium citrate as a reducing agent to obtain an Ag-GQDs nanocomposite. In order to reduce the toxicity of silver nanoparticles and improve the biocompatibility of nanoparticles, carboxymethyl inulin (CMI), a modification of natural polysaccharide inulin, is coupled with carbodiimide and nanocomposites to obtain Ag-GQDs-CMI. Hyaluronic acid (HA), as a target component of CD-44 (cancer stem cell marker), is connected to Ag-GQDs through an EDC-NHS coupling reaction, so that the synthesized HA-Ag-GQDs-CMI can reach cancer cells 


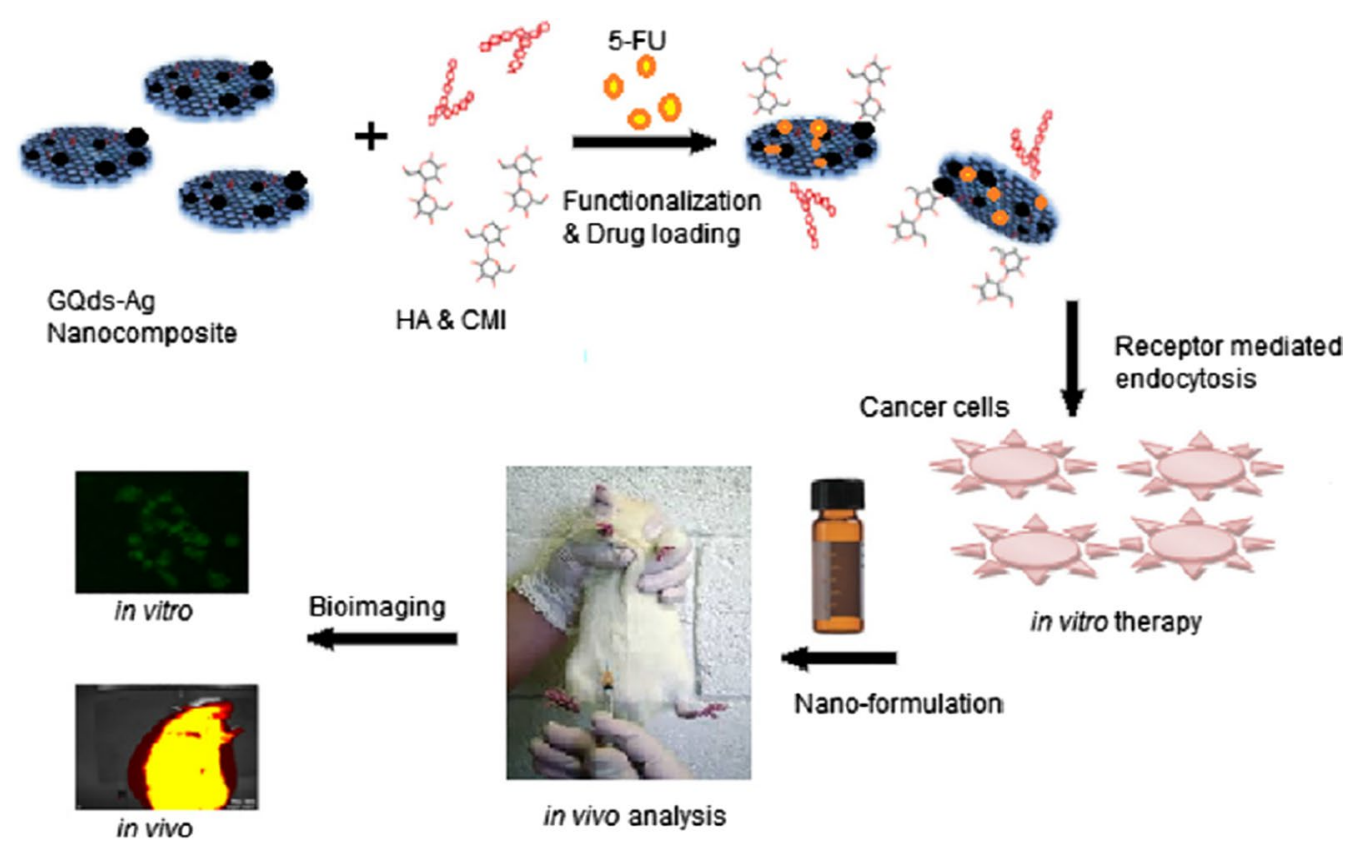

Fig. 18 Schematic diagram of nanoformulation preparation and in vitro and in vivo theranostic applications (reprinted/reproduced with the permission of Ref. [195], copyright 2017, Materials Science and Engineering: C)

accurately. ability. 5-Fluorouracil (5-FU), as a model drug, is loaded on it by adsorption and released in the acidic environment of cancer cells. After in vitro biological characterization of three cell lines-HeLa (Cervical cancer), HepG2 (Liver cancer), and Panc-1 (Pancreatic cancer)-in vitro and in Wistar rats, a synthetic 5-FUcontaining DDRS was found (72-78\% inhibition) inhibited cancer cells more effectively than Ag-GQDs-CMI $(\sim 56 \%)$ with 5 -FU and had stronger anti-cancer effect. This shows the potential promise of Ag-GQDs-CMI in targeted delivery-release drugs.

The most commonly used delivery-release mode is the ligand-pH delivery-release mode. Synthetic DDRS is typically nano-sized and reaches the tumor site through blood flow. Due to the unique ligand-receptor binding, drug delivery is accurate. However, because the release is $\mathrm{pH}$-mediated, the drug is sometimes lost during the delivery, which leads to a decrease in the treatment efficiency.

\section{EPR-photothermal delivery-release mode}

In the EPR-photothermal delivery-release mode, DDRS can be two-dimensional (2D) or three-dimensional (3D), but because it lacks a ligand and does not have a targeting function, it has no magnetic iron oxide and is not controlled by a magnetic field. Generally, it can only be accumulated at the tumor site through the EPR effect, but the release of DDRS can be controlled by NIR radiation without relying on the tumor's slightly acidic environment.

$\mathrm{Xu}$ et al. [123] reports a DDRS that can reduce the drug leakage and improve drug release efficiency in tumor lesions (Fig. 19). First, polymerizable ionic liquid $\mathrm{ViDoIm}^{+} \mathrm{Br}^{-}$as an emulsifier successfully prepared polymer microsphere including GQDs, DOX, MMA, and EGDMA via miniemulsion polymerization. The study found that compared with non-imprinted polymers (GNIPs), molecularly imprinted polymers (GMIPs) greatly improved the loading efficiency of DOX and reduced drug leakage. DDRS can accumulate in tumor areas through the EPR effect. In addition, because GQDs have a light-to-heat conversion effect, DOX that releases the load from GMIPs can be controlled by NIR radiation. The combination of molecular imprinting technology and photothermal controllable drug delivery system provides an idea for designing novel DDRS that can reduce drug loss and improve drug release efficiency.

Aiming at the targeting and penetration of deep tumors, Su et al. [196] has synthesized a pH-sensitive GQDs nanoaircraft (SCNA) with variable size and NIRmediated drug release, which can deliver and penetrate antitumor drugs into the deep Tumor (Fig. 20). Firstly, using hexaphenylbenzene as a starting material, artificial graphite (AG) was synthesized by a bottom-up method. Subsequently, Hummers method was used to prepare artificial graphene oxide (AGO) from AG, followed by 


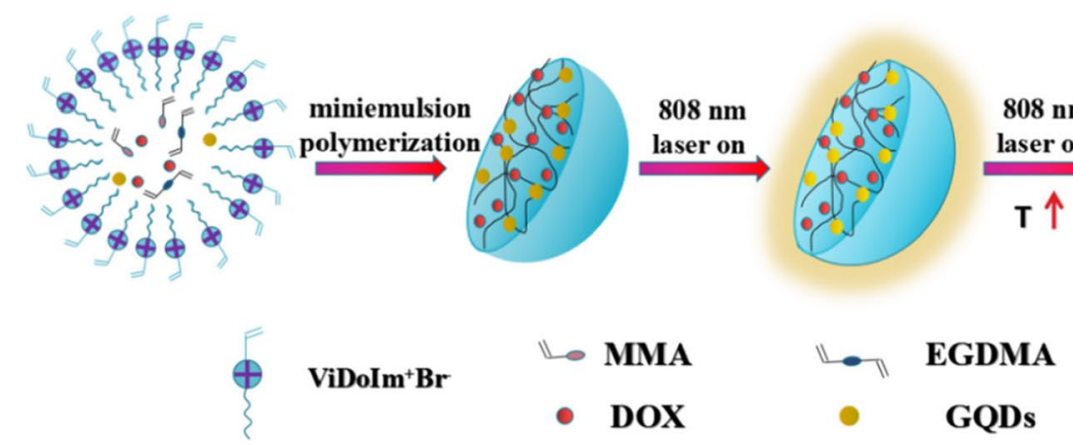

Fig. 19 Schematic diagram of GMIPs synthesis and DOX release by an ex vivo (reprinted/reproduced with the permission of Ref. [123], copyright 2019, Journal of Materials Science)

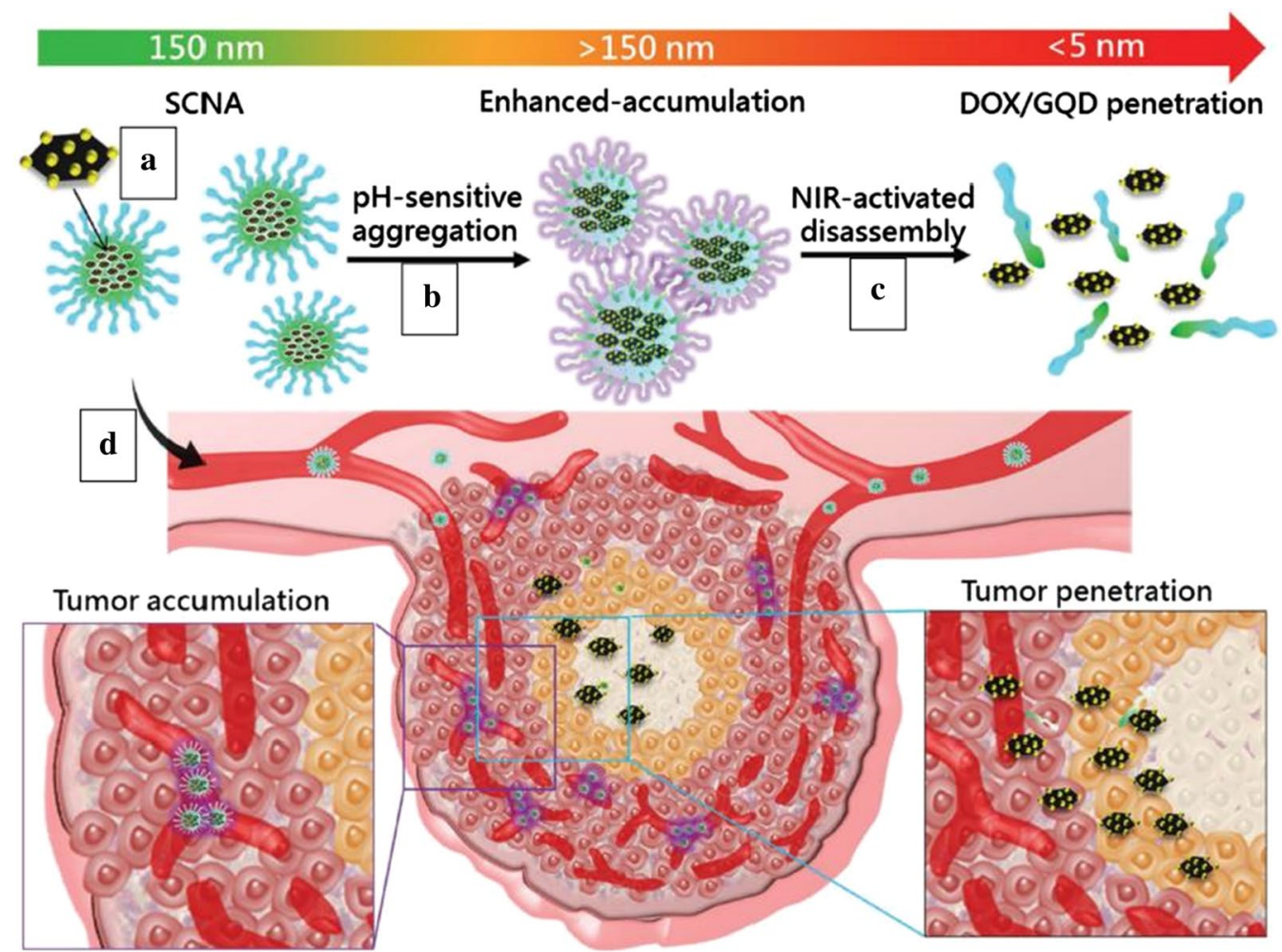

Fig. 20 Size-changeable nanoaircrafts (SCNAs) for hierarchical tumor targeting through an aggregation transition in the weak acidity of the tumor environment and photopenetrating drug/GQDs delivery. a The SCNAs delivered DOX/GQDs to the tumor through intravenous injection. $\mathbf{b}$ The aggregation transition of the SCNAs in the weak acidity of the tumor environment enhanced tumor accumulation. $\mathbf{c}$ NIR-activated disassembly of SCNAs into DOX/GQDs facilitated penetration deep into tumors. $\mathbf{d}$ Schematic illustration of the enhanced tumor accumulation and penetration by SCNAs (reprinted/reproduced with the permission of Ref. [196], (reprinted/reproduced with the permission of Ref. [196], copyright 2017, Advanced Functional Materials)

ultrasonic dispersion of the AGO solution containing hydrazine to obtain GQDs. Finally, GQDs loaded with DOX through $\pi-\pi$ stacking interactions self-assembled into SCNA with HTPGS containing a hydrophilic PEG strain and a hydrophobic vitamin $\mathrm{E}$ via hydrophobic interaction. The SCNA is injected into RG2 tumor-bearing $\mathrm{BALB} / \mathrm{c}$ nude mice via intravenous injection and has a stealth function due to stability at physiological $\mathrm{pH}$. When the SCNA entered the weak acidity of tumor environment through the enhanced permeability and 
retention (EPR) effect, it exhibited an aggregation transition, which expanded from 150 to $450 \mathrm{~nm}$ (in vitro $\mathrm{pH}$ 6.6). When further driven by NIR, SCNA breaks down into DOX/GQDs $(5 \mathrm{~nm})$ and penetrates deep tumor tissues like a bomb-loaded jet. It is exciting that DOX/ GQDs that penetrate tumor tissue can infect and repeatedly kill adjacent tumor cells without causing damage to the distal end. This nanocomposite with enhanced tumor permeability combined with photothermal chemotherapy is expected to open a new way to overcome the limitations of nanoparticles in tumor treatment.

Compared with the EPR-pH delivery-release mode, the EPR-photothermal delivery-release mode goes one step further. Instead of relying solely on the tumor's microacid environment, it has a light-to-heat conversion capability and can control the release of DDRS through NIR radiation. This approach reduces the early release of drugs and improves the efficiency of drug treatment.

\section{Core/Shell-photothermal/magnetic thermal delivery-release mode}

Some researchers [187, 188] have developed core-shell materials, which are generally combined with photodynamic therapy and thermodynamic therapy, providing new ideas for drug delivery and release.

With upconversion nanoparticle (UCNP) as the core and GOQDs as the shell, Choi et al. [197] also synthesized a core-shell nanoparticle for cell imaging and drug delivery. Firstly, UCNP $\left(\mathrm{NaYF}_{4}: \mathrm{Yb}^{+}, \mathrm{Er}^{+}\right)$was synthesized by hydrothermal method, and the surface of UCNP was further modified by polyethylene glycol 2-aminoethyl ether acetic acid (amine-PEG). GOQDs were coupled to Hypocrellin A (HA), a commonly used chemotherapeutic drug and photosensitizer, through $\pi-\pi$ interaction and loaded onto the surface of UCNP via PEG to synthesize HA/GOQDs/UCNP core-shell structure (Fig. 21). HeLa cells were used to study HA/GOQDs/UCNP in vitro. The study found that GOQDs/UCNP and HA/GOQDs had no significant cytotoxicity regardless of whether they were irradiated (460 nm LED). Compared with the nonirradiated group, the cell activity of the HA/GOQDs/ UCNP irradiated group was significantly reduced (52\%), indicating that HA/GOQDs/UCNP irradiation at $460 \mathrm{~nm}$ improved the anti-tumor treatment effect. Upconversion luminescence (UCL) imaging shows that HA/GOQDs/ UCNP is an effective biological probe that can be used for cell imaging. Synthetic core-shell structured nanoparticles are potential candidates for multifunctional agents for cell imaging, drug delivery, and cell therapy.

Yao et al. [141] established a multifunctional platform for drug release, magnetic thermotherapy and photothermotherapy, consisting of caps and local photothermal generators, drug carriers and magnetic thermoseeds. Firstly, magnetic mesoporous silica nanoparticles (MMSN), drug carriers and magnetic thermoseeds were synthesized by sol-gel process with magnetic $\mathrm{Fe}_{3} \mathrm{O}_{4}$ nanoparticles prepared by solvothermal method as the core. Next, APTES-functionalized amine-modified MMSN

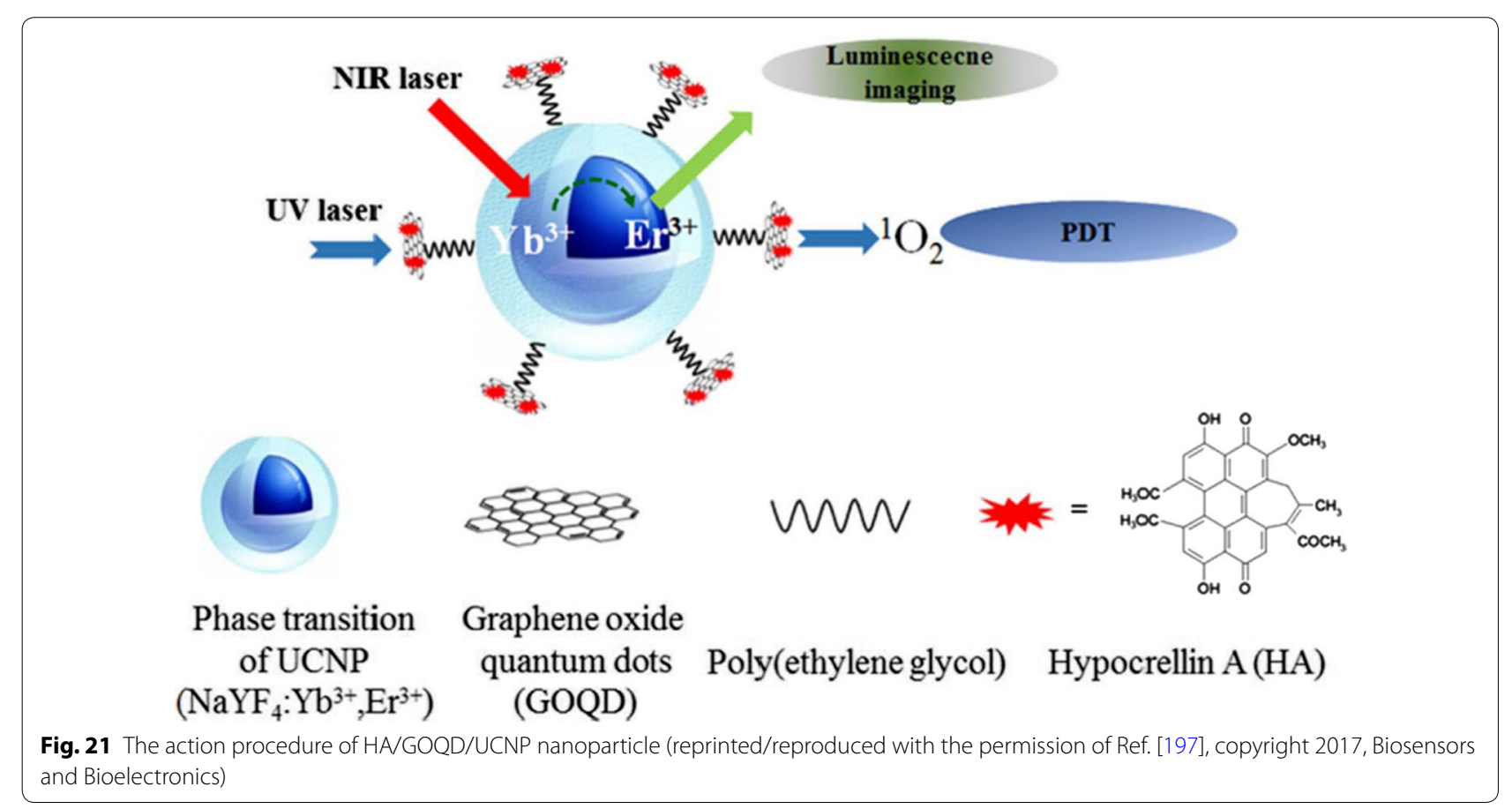




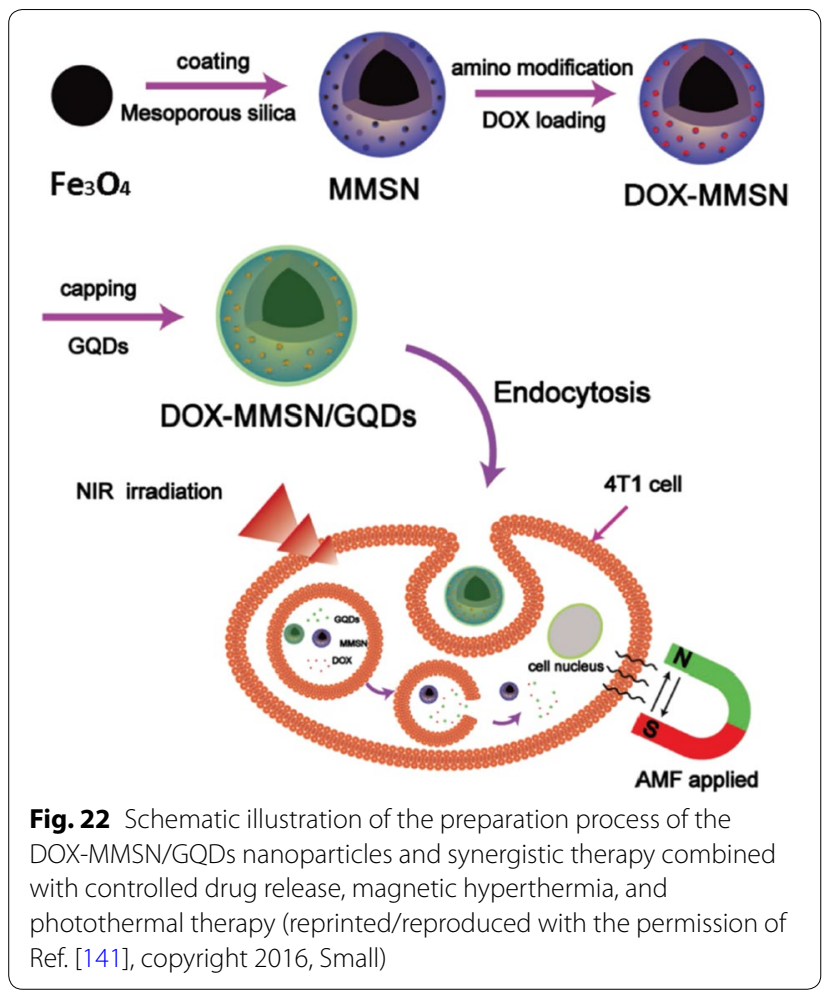

absorbed DOX by stirring in the dark for $24 \mathrm{~h}$. Then, DOX-MMSN and the activated GQDs were mixed at $4{ }^{\circ} \mathrm{C}$ in the dark for DOX encapsulation. $\mathrm{N}$-Hydroxysuccinimide (NHS) and 1-ethyl-3-(3-dimethylaminopropyl) carbodiimide hydrochloride (EDC) activate GQDs as caps and local photothermal generators. Finally, a core-shell structure of MMSN/GQDs DDRS with a diameter of $100 \mathrm{~nm}$ was obtained (Fig. 22). In vitro biological detection of MMSN/GQDs DDRS was carried out using breast cancer line $4 \mathrm{~T} 1$ cells as model cell system. It was found that the release of DOX in DOX-MMSN/GQDs could be induced in a low $\mathrm{pH}$ environment to perform chemotherapy of tumor cells. In addition, this DDRS can effectively heat cells to high temperature under alternating magnetic fields or NIR radiation for magnetic or photothermal treatment of tumor cells. Compared with incomplete DDRS treatment, the combined use of chemotherapy, magnetocaloric therapy, or photothermal therapy has a significant synergistic effect greatly improving the antitumor efficiency. Therefore, this multi-functional platform (MMSN/GQDs DDRS) that enhances anti-tumor efficiency has a great potential application in anti-tumor treatment.

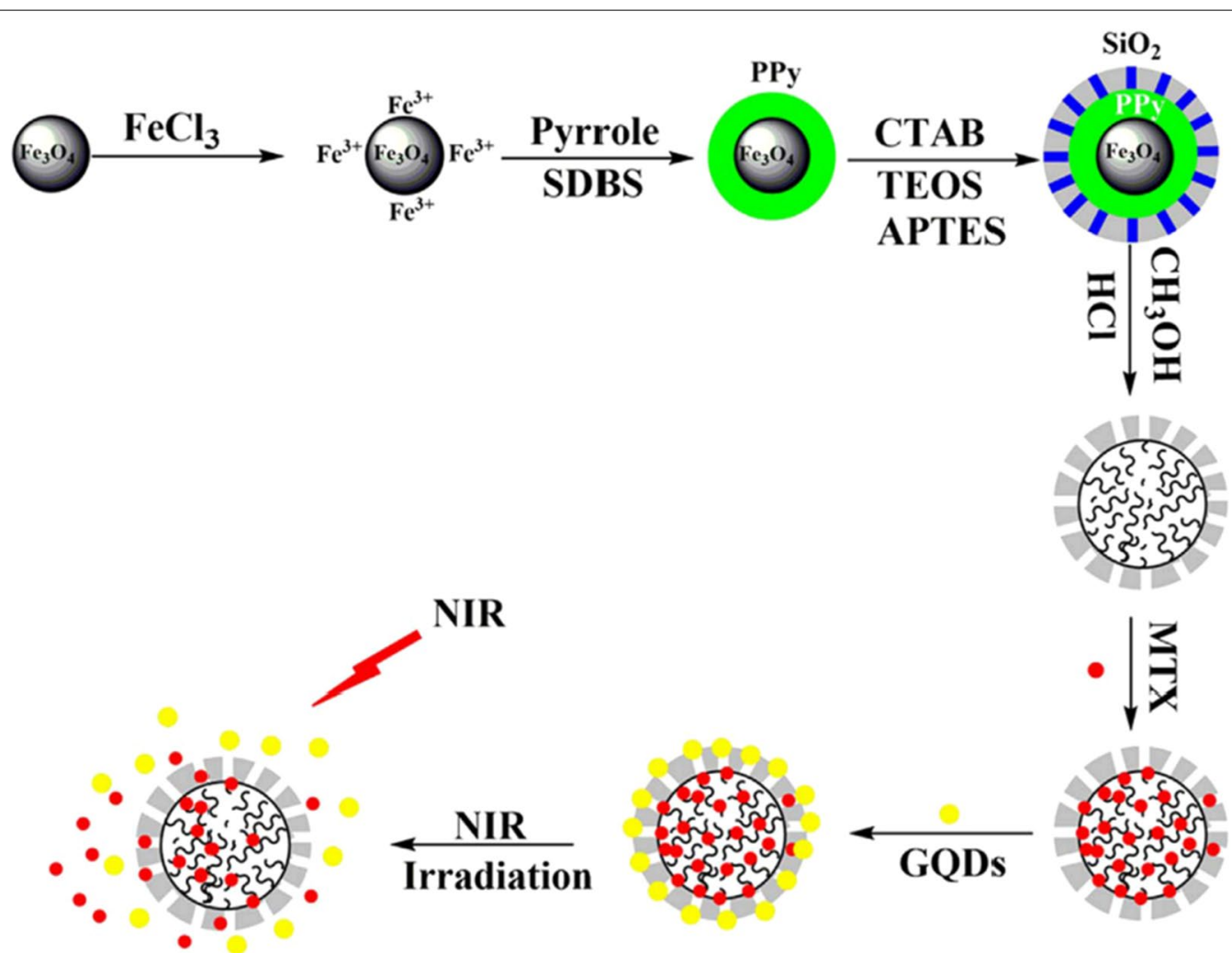

Fig. 23 Schematic illustration showing the synthesis of $\mathrm{PPy} / \mathrm{mSiO}_{2}$, the encapsulation of MTX with the aid of GQDs cap and the NIR light-triggered MTX delivery (reprinted/reproduced with the permission of Ref. [198], copyright 2017, Materials Science and Engineering: C) 
In order to reduce drug loss during transportation, $\mathrm{Li}$ et al. [198] synthesized polypyrrole/mesoporous $\mathrm{SiO}_{2} /$ GQDs ( $\mathrm{PPy} / \mathrm{mSiO}_{2} / \mathrm{GQDs}$ ) core-shell nanocomposites (Fig. 23) for drug delivery. Firstly, using $\mathrm{Fe}_{3} \mathrm{O}_{4}$ as the core, $\mathrm{Ppy}-\mathrm{Fe}_{3} \mathrm{O}_{4}$ was prepared. Polypyrrole (PPy), has a very high light-to-heat conversion efficiency at $808 \mathrm{~nm}$ and shows strong absorption in the NIR region. Subsequently, a mesoporous $\mathrm{SiO}_{2}$ layer was formed on the surface of $\mathrm{PPy}-\mathrm{Fe}_{3} \mathrm{O}_{4}$, and $\mathrm{Fe}_{3} \mathrm{O}_{4}$ was removed to form a PPy/ $\mathrm{mSiO}_{2}$ core-shell structure. After stirring the MTX load, GQDs were introduced into the outer surface of PPy/ $\mathrm{mSiO}_{2}$, forming hydrogen bonds with the outer surface of $\mathrm{mSiO}_{2}$, thereby packaging the drug to prevent the drug from being lost during transportation. Under NIR radiation from the tumor site, PPy converts light into heat. As the temperature of $\mathrm{PPy} / \mathrm{mSiO}_{2} / \mathrm{GQDs}$ increased, the hydrogen bonds between GQDs and $\mathrm{mSiO}_{2}$ were broken and fell off. MTX was released from $\mathrm{PPy} / \mathrm{mSiO}_{2}$ for antitumor treatment. The intelligent drug delivery-release of $\mathrm{PPy} / \mathrm{mSiO}_{2} / \mathrm{GQDs}$ could provide a new mechanism for medical diagnosis and treatment.

Loading the antitumor drug into the core-shell structure can effectively prevent the early release of drug during the delivery. Under the irradiation of light or applying magnetic field, the cell penetration efficiency and cell absorption capacity of nano-sized core-shell structure could be significantly improved, thereby improving the tumor treatment efficacy. In addition to chemotherapy, photothermal therapy and magnetocaloric therapy have also been developed, and with extensive studies by researchers, multiple therapeutic approaches in conjunction with antitumor have gradually become a trend for tumor therapy [144].

\section{Other delivery-release modes}

Some researchers have also developed other deliveryrelease modes using GQDs. In addition to synthesizing nanoscale DDRS for intravenous administration, GQDs can also be used for micro and millimeter DDRS for oral administration. In order to avoid the trauma and discomfort caused by intravenous or other methods of administration, for some diseases, oral delivery systems have also attracted much attention.

Hydrogel nanocomposite microspheres prepared based on carboxymethylcellulose (CMC) have received widespread attentions due to their many advantages, such as mild, simple, compact, and uniform shape to be used for drug delivery and release. Therefore, Javanbakht et al. [199] synthesized hydrogel nanocomposite microspheres based on CMC and GQDs for oral administration (Fig. 24). Firstly, CA prepared GQDs by pyrolysis, and then pre-loaded the model drug naproxen (NPX) on the surface of GQDs by stirring to form GQDs-NPX (Fig. 25)
[113]. CMC was further added, and copper acetate was added as a physical cross-linking agent under continued stirring. Finally, $\mathrm{Cu}$-crosslinked carboxymethylcellulose/naproxen/graphene quantum dots nanocomposite hydrogel beads ( $\mathrm{Cu}-\mathrm{CMC} / \mathrm{NPX} / \mathrm{GQDs})$ were obtained after drying at room temperature. After simulating oral administration, the release of the drug in the gastrointestinal tract found that CMC can effectively protect the loaded drug from the effects of a low $\mathrm{pH}$ environment. By controlling the release of different $\mathrm{pH}$ environments, the long-term effects of the drug can be extended. Caco-2 cells was used to detect the cytotoxicity of $\mathrm{Cu}-\mathrm{CMC} /$ NPX/GQDs. It was found that the prepared hydrogel nanocomposite beads had no obvious toxicity and could be used as drug capsules to form an oral drug deliveryrelease system in the gastrointestinal environment.

Subsequently, they [200] developed new bio-nanocomposite beads for oral administration. First, using the previously prepared GQDs [113, 199] as a cross-linking agent, the beads of chitosan (CS) acetate solution prepared by a syringe ( $2 \mathrm{~mm}$ diameter) were cross-linked. CS-GQDs bio-nanocomposite hydrogel beads were obtained after vacuum drying. Afterward, CS-GQDs were loaded with SS by immersing in the model drug sodium salicylate (SS) solution to form CS-GQDs/SS. Next, CS-GQDs/SS was encapsulated and protected by $\mathrm{pH}$-sensitive $\mathrm{CMC}$ by means of stirring and syringe extrusion, and finally $\mathrm{Fe}^{3+}$ cross-linking was carried out with ferric chloride hexahydrate solution. After drying, the CMC encapsulated CS-GQDs/SS bio-nanocomposite hydrogel beads (CS-GQDs/SS@CMC) were synthesized (Fig. 26). After simulated oral administration in vitro, it was found that the prepared beads were stable under the conditions of the gastrointestinal tract and could prolong the stability of administration for a long time (Fig. 27). MTT test of human colon adenocarcinoma HT29 cells showed that the bio-nanocomposite beads had low cytotoxicity. In conclusion, the new CS-GQD/SS@CMC is expected to potentially serve as a safe carrier for oral administration.

Based on MGQDs, Justin et al. [201] also combined chitosan $(\mathrm{CH})$ and water-soluble PEG ring to synthesize a biodegradable detachable microneedle array, $\mathrm{CH}$ MGQDs (Fig. 28). The release of CH-MGQDs to small molecular weight (MWt) drugs such as LA and bovine serum albumin (BSA) was also investigated. The results indicate that $\mathrm{CH}$-MGQDs with intrinsic photoluminescent and supermagnetic properties are potential materials for the development of multifunctional microneedles for targeted and tracking percutaneous administration.

The advantages and disadvantages of different drug delivery-release modes are compared (Table 3). Given the low $\mathrm{pH}$ of the tumor microenvironment, researchers 

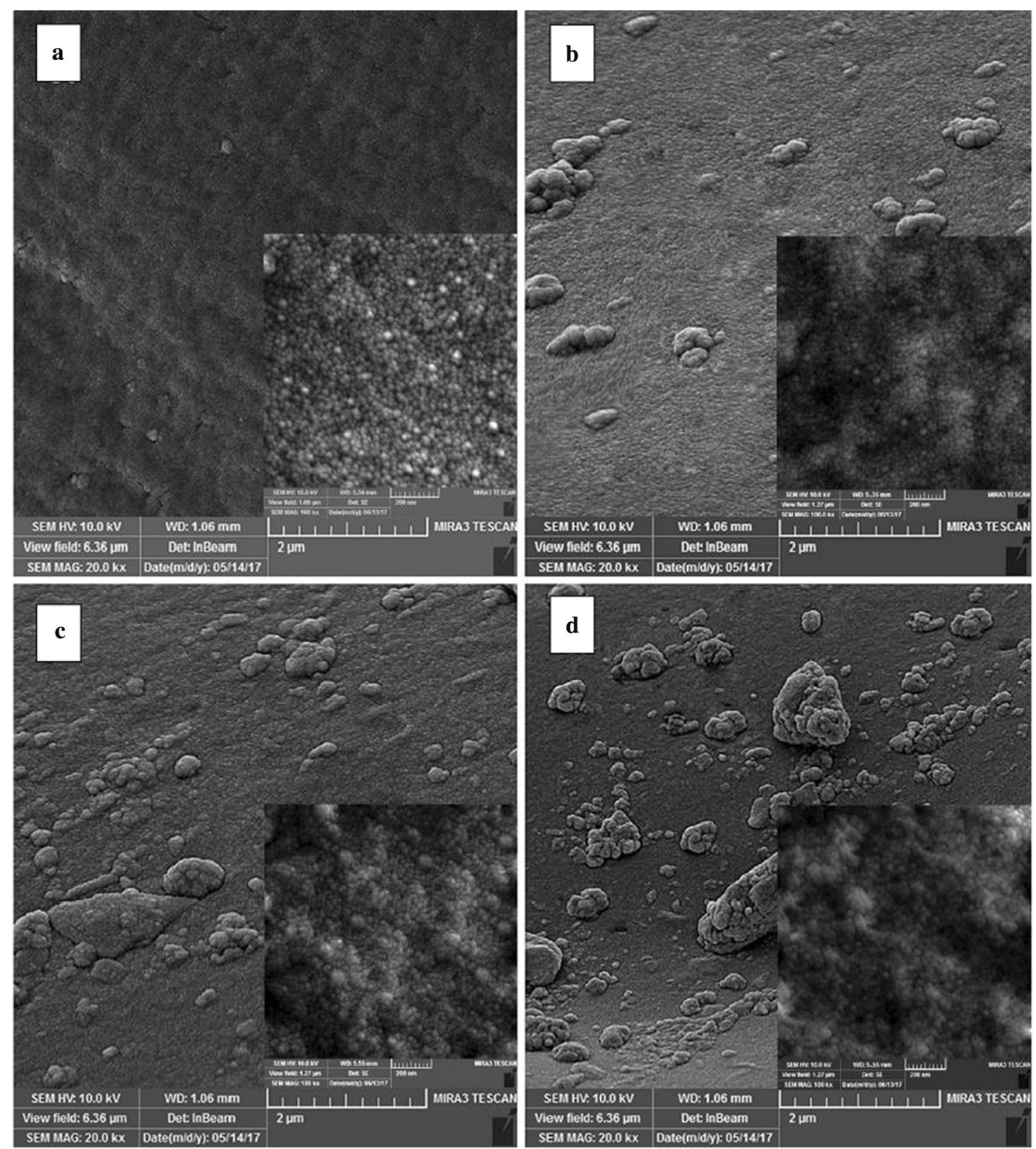

Fig. 24 SEM images of the a Cu-CMC/NPX and Cu-CMC/NPX/GQDs, b 10\%, c 20\%, d 30\% GQDs content (insets are higher magnifications) (reprinted/reproduced with the permission of Ref. [199], copyright 2018, Carbohydrate polymers)

have developed an EPR-pH delivery-release mode. The drug loading efficiency in this mode is $~ 82.5 \%$ [41], and the drug release efficiency at $\mathrm{pH} 7.4$ is $99 \%$ at $24 \mathrm{~h}$ in the previous report [184]. However, a small part of the drug will be released early due to $\mathrm{pH}$ changes during delivery. Considering that ligand-receptor binding enables more accurate drug delivery, a ligand-pH delivery-release mode was developed. Unfortunately, the drug loading efficiency and release efficiency decreased to $60 \%$ and 50\% [193], respectively. Moreover, such DDRS can effectively release a large amount of antitumor drugs only after the low $\mathrm{pH}$ microenvironment of the tumor is formed. With the development of light-to-heat conversion materials and magnetic-to-heat conversion materials, EPR-Photothermal delivery-release mode have emerged. Although it cannot target antitumor, it avoids the disadvantages 

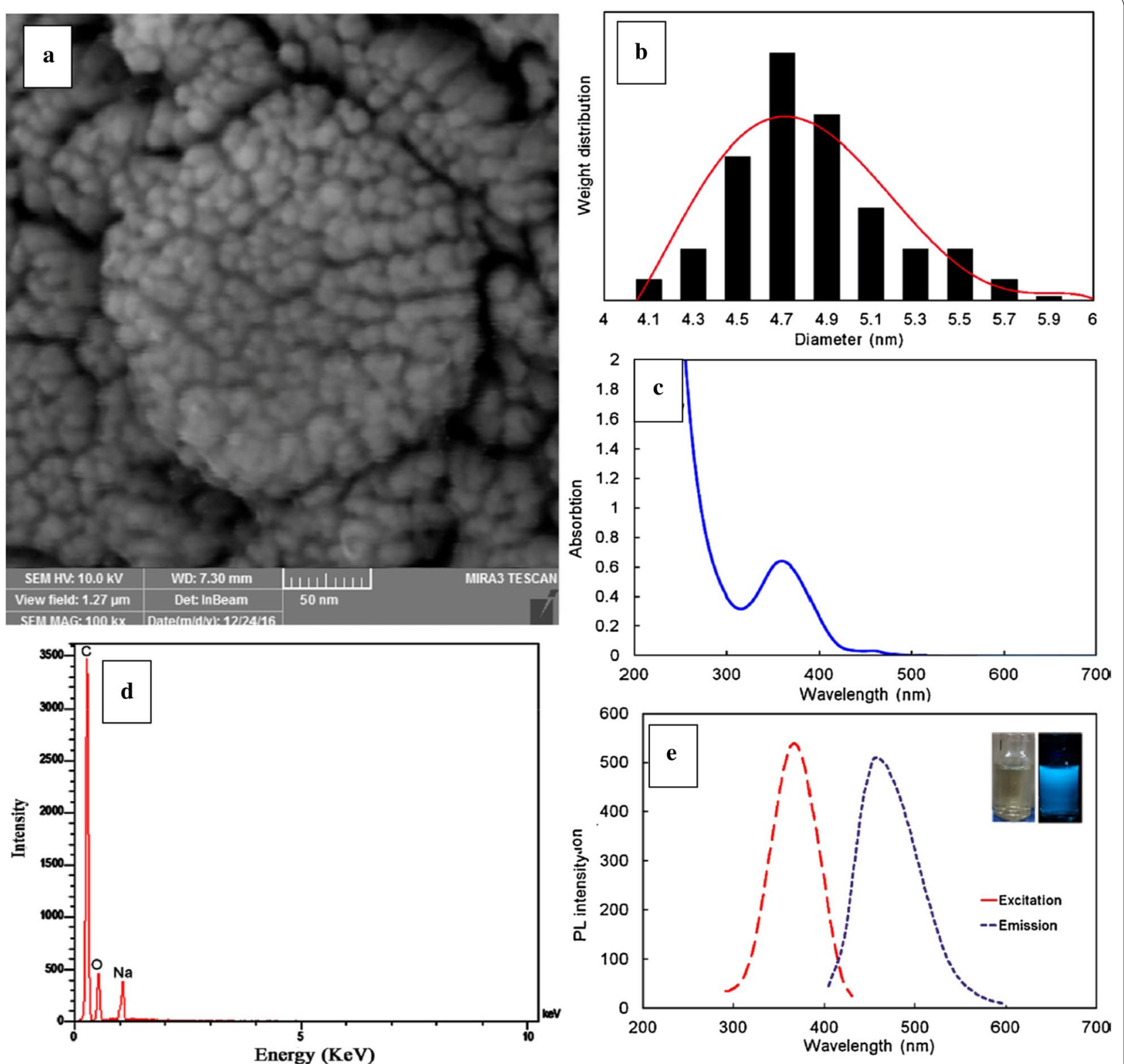

Fig. 25 Characterization of GQDs: a SEM, b DLS of GQDs, c UV-Vis absorption spectra of GQDs in water, $\mathbf{d}$ EDX analysis for the prepared GQDs, e PL spectrum of the dilute aqueous solution of GQDs and the photograph demonstrates the fluorescence of a dilute aqueous solution of GQDs (reprinted/reproduced with the permission of Ref. [199], copyright 2018, Carbohydrate polymers)

of relying solely on $\mathrm{pH}$ to release the drug, which can improve drug release and thus improve the efficiency of chemotherapy. The drug loading efficiency and release efficiency were $70.8 \%$ and $\sim 40 \%$ ( $3 \mathrm{~h}$ ), respectively [123]. The previously reported drug loading efficiency reached 97\% [196]. The core/shell-photothermal/magnetic thermal delivery-release mode exhibits excellent anti-tumor potential. Not only does it avoid the premature release of the drug before it is delivered to the tumor site, it also enables drug release and tumor cell thermal ablation at specific sites. For other diseases, other methods have also been developed, such as oral preparations and microneedle array. In terms of current reports, both drug loading efficiency and release efficiency still need to be greatly improved. In addition, the impact of the microenvironment in animals on DDRS is still unclear, and DDRS research needs to be transferred from the cell research stage to the animal research stage.

In addition, GQDs have PL characteristics; therefore they can track drugs for biological imaging. GQDs have 


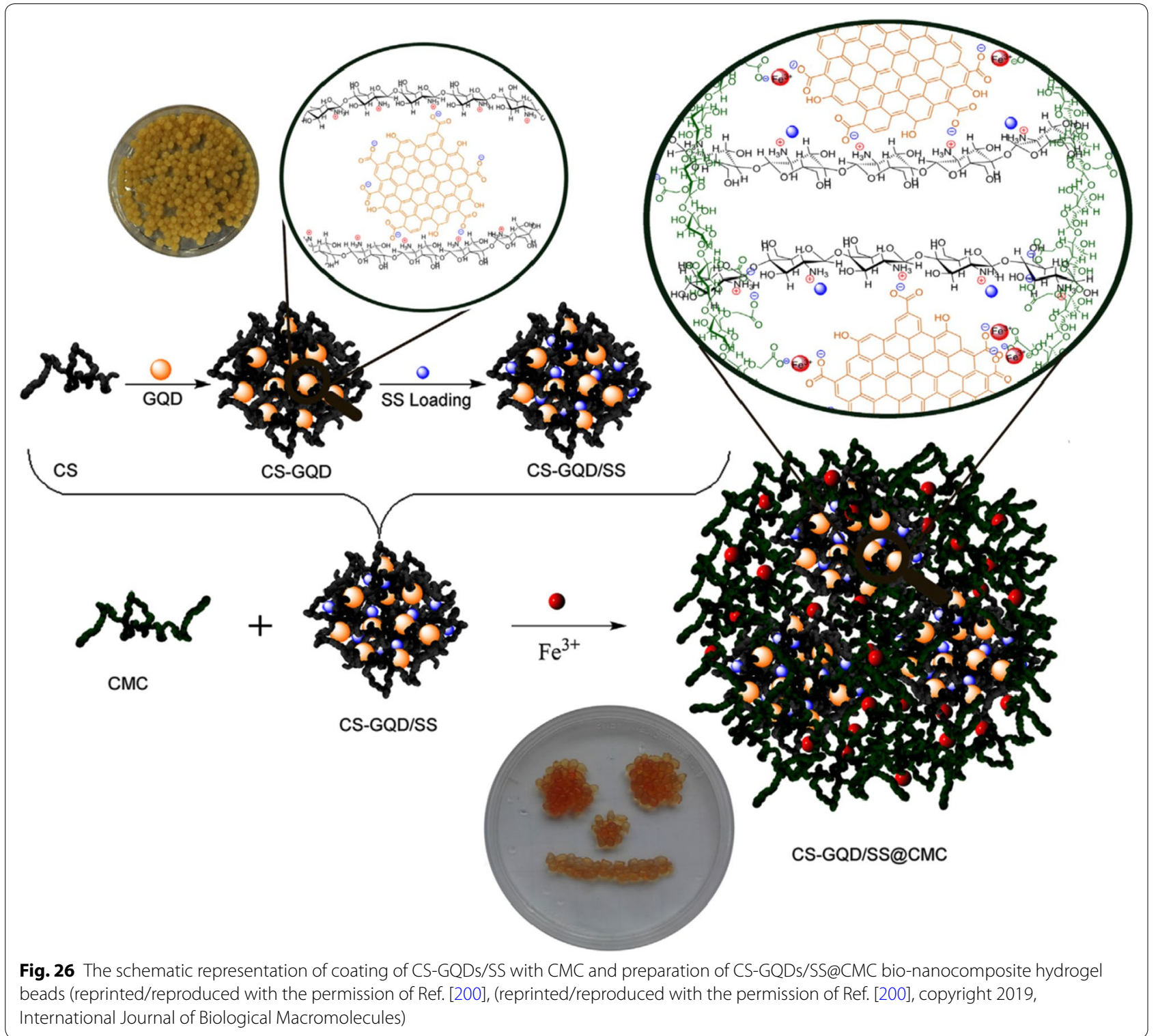

limited functions, hence, in order to design multifunctional DDRS, multiple elements and groups are usually doped inside the GQDs. Moreover, even though the simulation results can provide good insights about the possible treatment efficacy in vitro, the practical in vivo approaches should not be overlooked. At present, the performance of some potential DDRSs are successfully confirmed through in vitro tests, however, due to the more complexity of in vivo tests the performance of testing DDRS in tumor-bearing mice needs to be more accurately studied.
Gene, peptide, and other drugs delivery

Although most researches focus on tumor-targeted drug delivery, GQDs have shown promising potentials for delivery of other molecules such as DNA, peptides. An important technique of gene therapy is to delivery nucleic acids (DNA or RNA) to cells to restore or add gene expression, for the purpose of treating disease. Owing to its small size, GQDs possess the ability to cross the blood-brain barrier (BBB), this allows to ensure delivery of the nucleic acid payloads into cell cytosols and nuclei. Together with its low toxicity, good stability and luminescence properties which enable easy monitoring of drug release, GQDs is an excellent candidate for gene carriers. Plasmid DNA (pDNA) was proved 

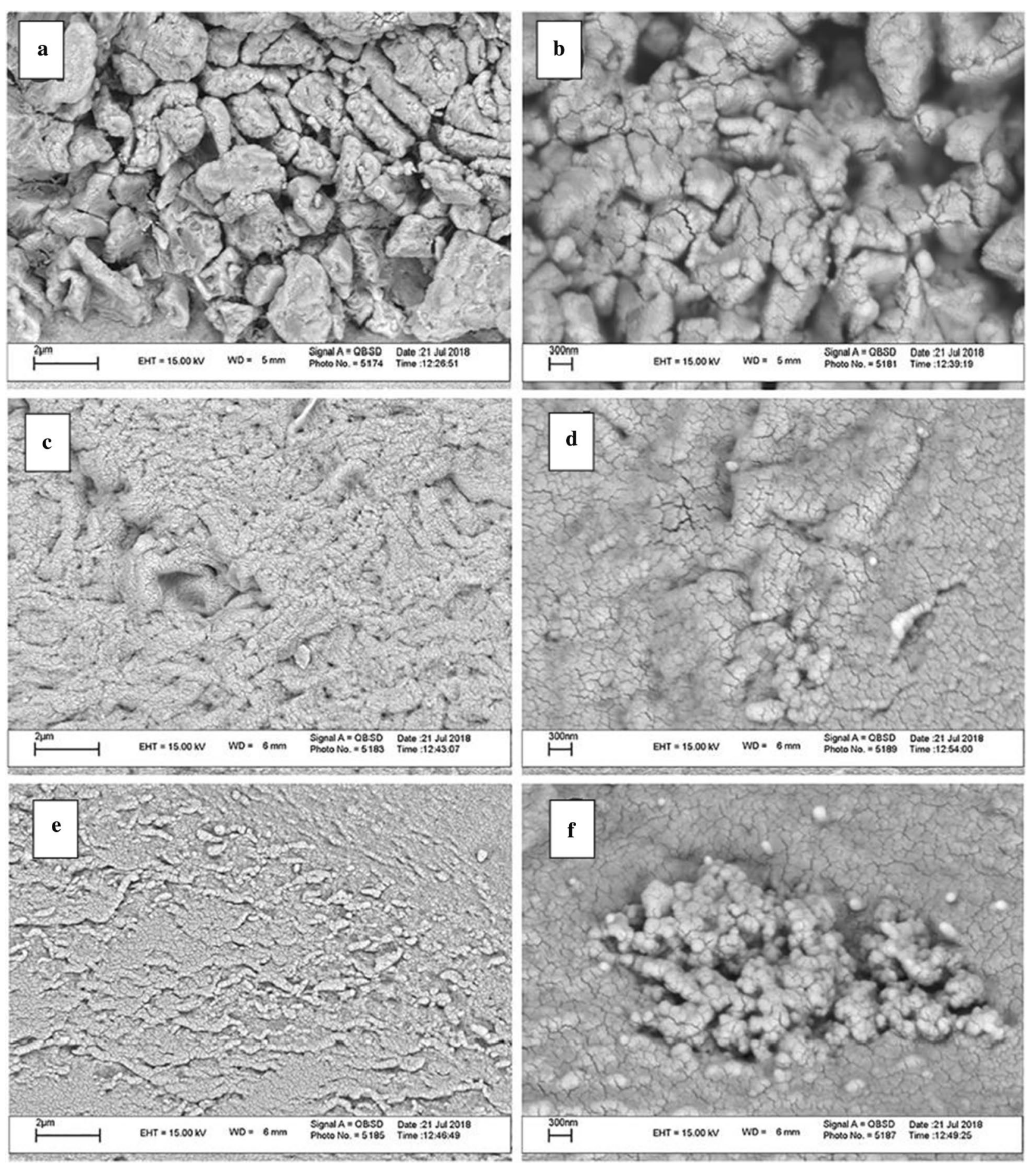

Fig. 27 SEM images of the a CS-GQDs, c CMC@SS, e CS-GQDs/SS@CMC at low magnification and SEM images of the b CS-GQDs, d CMC@SS, fCS-GQDs/SS@CMC at high magnifications (reprinted/reproduced with the permission of Ref. [200], copyright 2019, International Journal of Biological Macromolecules)

to be conjugated with GQDs and MPG-2H1 chimeric peptide to form the GQDs-peptide-pDNA complex via non-covalent interactions. GQDs were found to allow efficient tracking due to their green and red emissions and enhance internalization of the plasmid harboring firefly luciferase gene into HEK 293T cells. This study 


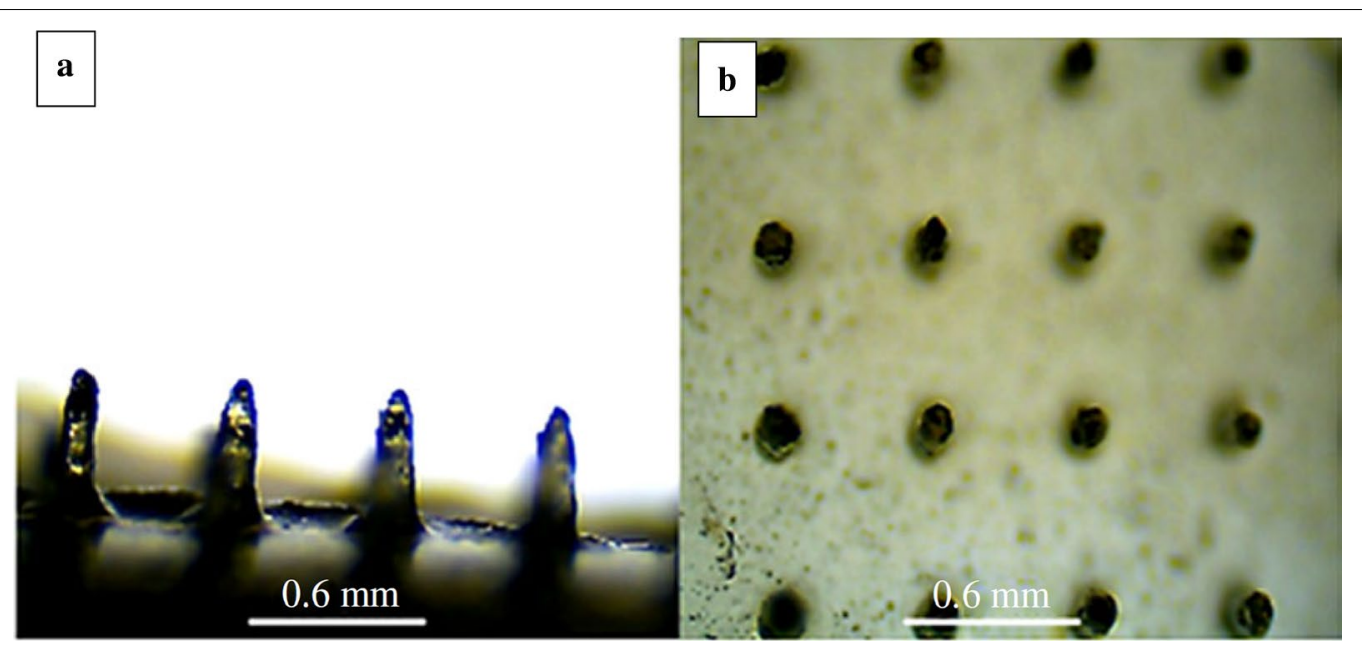

Fig. 28 Optical micrographs of the CH-MGQDs microneedle array: a side view and $\mathbf{b}$ plan view (reprinted/reproduced with the permission of Ref. [201], copyright 2018, Interface Focus)

suggested the GQDs-peptide-pDNA complex could be a promising vector for enhanced the transfection efficiency and tracking of pDNA in vitro and in vivo [126].Glycineproline-glutamate (Gly-Pro-Glu, GPE), as a neuroprotective peptide, was conjugated with GQDs in a recent study. The results indicated that GQDs could be used as a novel nanocarrier to delivery neuroprotective peptide GPE to Central Nervous System (CNS), the GPE-GQDs can inhibit the aggregation of amyloid- $\beta(A \beta)$ and reduce the inflammatory response, further protect the synapse and promote the neurogenesis [202].

GQDs also showed promising potential in transport Vanadium compounds, a kind of anti-diabetic agents. Vanadium coordination compounds [VO(p-dmada)] were proved to be packed on one side of the GQD sheets by the $\pi-\pi$ stacking interaction. In vivo tests suggested that GQD-VO(p-dmada) exhibited improved pharmaceutical properties and enhanced anti-diabetic effects compared to $\mathrm{VO}$ (p-dmada) alone [203].

At present, the research and application of GQDs in drug delivery is still in its initial stage, however, the great potential of GQDs based nanocarriers has been proved already, we have reason to believe that more types of drugs can be delivered by this novel nanomaterial.

\section{Conclusion and prospect}

This review focuses on the recent advances in the synthesis of GQDs and their applications in drug delivery. Several fabrication methods of GQDs are introduced, while some popular techniques such as hydrothermal method, microwave method, and molecular carbonization method are emphasized. Each of these fabrication methods has advantages and drawbacks that we should balance with the needs for a specific application. Furthermore, novel functionalization methods have been developed to improve the physicochemical characteristics of GQDs so that they can meet the high requirements for biomedical applications.

In addition, various drug release-delivery modes of GQDs-based drug release systems are reviewed. By analyzing the advantages and disadvantages of various types of DDRS, the trend of designing new multifunctional DDRS is pointed out. GQDs have been proved to be able to not only delivery anticancer drugs in various DDRS modes, but also act as nanocarriers to transport gene, peptides, and other non-anticancer drugs. However, before their practical applications in biomedicine and clinical practice, many challenges need to be addressed. Despite of the large improvement in the biocompatibility of GQDs, systematic studies on their potential long-term toxicity and how GQDs affects the immune systems, reproductive systems, and nerve systems in different animal models are needed. GQDs synthesized with different ways exhibited tremendous variations in their physic-chemical properties. Conflicting claims with respect to the biological properties of GQDs have been reported, such as their inherent antibacterial ability. Therefore, a standard for characterization of GQDs is need and would help to understand more clearly about the various GQDs researches. In addition, the size of GQD has great influence on its toxicity, surface functionalization and the ability to across biological barriers. More systematic studies involving the size of GQDs are still need in the future.

Although, DDRS research for GQDs is still at its infancy, it is speculated that the future research can 


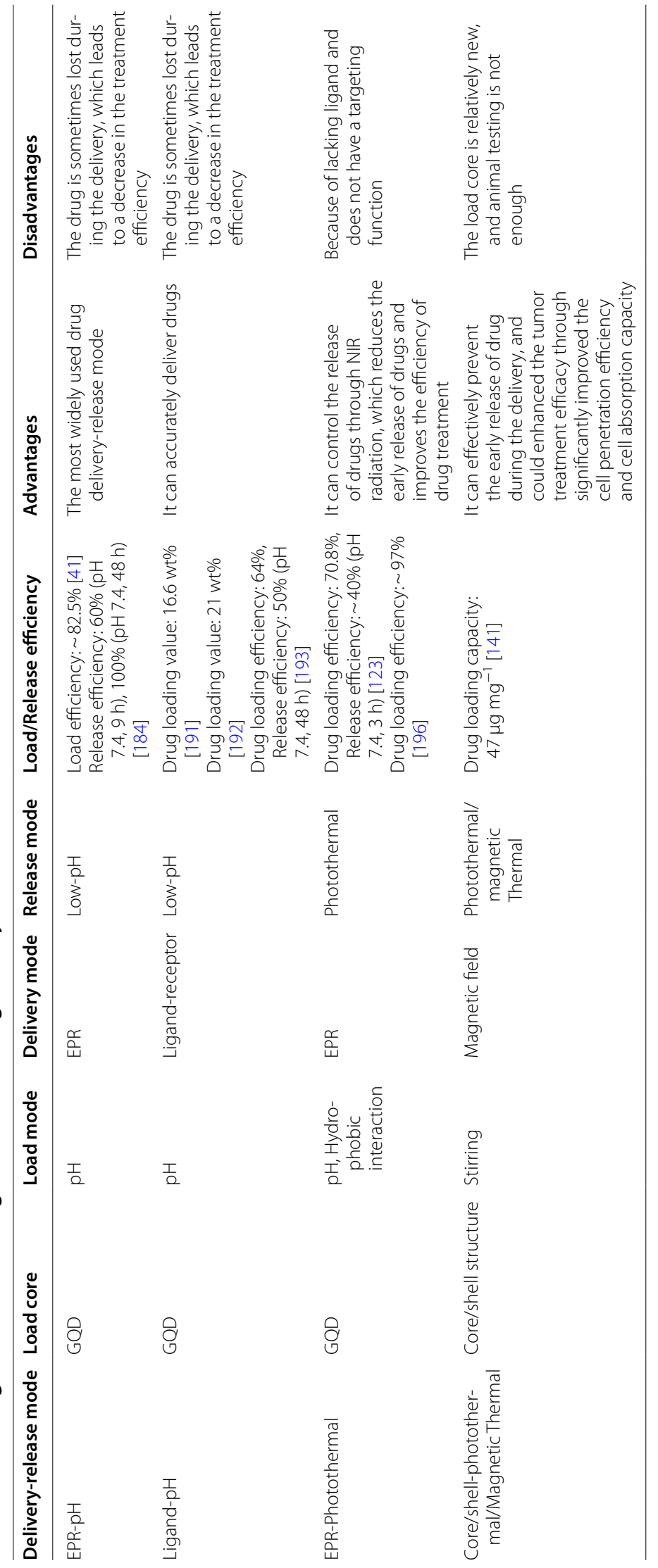


successfully resolve the current problems faced by implementation of GQDs to design more safe and simple synthesis routs for efficient and mass-production of DDRS.

\section{Acknowledgements \\ Not applicable.}

\section{Authors' contributions}

$\mathrm{CZ}, \mathrm{XS}$ and $\mathrm{YL}$ brought forward the subject and guided the writing; $\mathrm{CZ}, \mathrm{XS}$ wrote the manuscript with the help of MZ, YF, LY, NW, FW, LL, MM, and QZ and $J L$ provided outline of the manuscript. All authors contributed to the general discussion. All authors read and approved the final manuscript.

\section{Funding}

The authors acknowledge the financial support from the Swedish National Science Foundation with the contract No: 621-2007-4660, from the Swedish Board for Innovatoin (Vinnova) within the Siografen Program, from the Swedish Board for Strategic Research (SSF) with the contract GMT14-0045 and from Formas with the contract No: FR-2017/0009 as well as from the Key Scientific Research Projects of Higher Education of Henan Province, China (18A430026), the Natural Science Foundation of Henan Province, China (Grant No. 182300410107), and the National Natural Science Foundation of China (No. 51872182).

\section{Availability of data and materials}

The datasets used and/or analysed during the current study are available from the corresponding author on reasonable request.

\section{Ethics approval and consent to participate}

Not applicable.

\section{Consent for publication}

Not applicable.

\section{Competing interests}

The authors declare that they have no competing interests.

\begin{abstract}
Author details
${ }^{1}$ School of Life Sciences and Technology, Xinxiang Medical University, Xinxiang 453003, P. R. China. ${ }^{2}$ Electronics Materials and Systems Laboratory, Department of Microtechnology and Nanoscience, Chalmers University of Technology, 41296 Gothenburg, Sweden. ${ }^{3}$ SHT Smart High-Tech AB, 411 33 Gothenburg, Sweden. ${ }^{4}$ Department of Health Technology, Technical University of Denmark, 2800 Kongens Lyngby, Denmark. ${ }^{5}$ School of Automation and Mechanical Engineering, SMIT Center, Shanghai University, No 20, Chengzhong Road, Box 808, ShanghaiShanghai 201800, China.
\end{abstract}

Received: 26 May 2020 Accepted: 24 September 2020

Published online: 02 October 2020

\section{References}

1. Novoselov KS, Geim AK, Morozov SV, Jiang D, Zhang Y, Dubonos SV, Grigorieva IV, Firsov AA. Electric field effect in atomically thin carbon films. Science. 2004;306:666-9.

2. Jiao L, Zhang L, Wang X, Diankov G, Dai H. Narrow graphene nanoribbons from carbon nanotubes. Nature. 2009;458:877-80.

3. Kosynkin DV, Higginbotham AL, Sinitskii A, Lomeda JR, Dimiev A, Price BK, Tour JM. Longitudinal unzipping of carbon nanotubes to form graphene nanoribbons. Nature. 2009:458:872-6.

4. Bak S, Kim D, Lee H. Graphene quantum dots and their possible energy applications: a review. Curr Appl Phys. 2016;16:1192-201.

5. Zheng P, Wu N. Fluorescence and sensing applications of graphene oxide and graphene quantum dots: a review. Chem An Asian J. 2017;12:2343-53.
6. Yan Y, Gong J, Chen J, Zeng Z, Huang W, Pu K, Liu J, Chen P. Recent advances on graphene quantum dots: from chemistry and physics to applications. Adv Mater. 2019;31:e1808283.

7. DuY, Guo S. Chemically doped fluorescent carbon and graphene quantum dots for bioimaging, sensor, catalytic and photoelectronic applications. Nanoscale. 2016;8:2532-43.

8. Singh H, Sreedharan S, Tiwari K, Green NH, Smythe C, Pramanik SK, Thomas JA, Das A. Two photon excitable graphene quantum dots for structured illumination microscopy and imaging applications: lysosome specificity and tissue-dependent imaging. Chem Commun. 2019;55:521-4.

9. Qu C, Zhang D, Yang R, Hu J, Qu L. Nitrogen and sulfur co-doped graphene quantum dots for the highly sensitive and selective detection of mercury ion in living cells. Spectrochim Acta A Mol Biomol Spectrosc. 2019;206:588-96.

10. Li X, Guo H, Ren S, Fan R, Yu Y, Zhang H, Liu C, Miao L. Fluorescent labelling in living dental pulp stem cells by graphene oxide quantum dots. Appl Biochem Biotechnol. 2019;47:115-22.

11. Chen W, Lv G, Hu W, Li D, Chen S, Dai Z. Synthesis and applications of graphene quantum dots: a review. Nanotechnol Rev. 2018;7:157-85.

12. Nasrollahi F, Koh YR, Chen P, Varshosaz J, Khodadadi AA, Lim S. Targeting graphene quantum dots to epidermal growth factor receptor for delivery of cisplatin and cellular imaging. Mater Sci Eng C. 2019;94:247-57.

13. Xie Y, Wan B, Yang Y, Cui X, Xin Y, Guo LH. Cytotoxicity and autophagy induction by graphene quantum dots with different functional groups. J Environ Sci China. 2019;77:198-209.

14. Cui D, Tian F, Ozkan CS, Wang M, Gao H. Effect of single wall carbon nanotubes on human HEK293 cells. Toxicol Lett. 2005;155:73-85.

15. Akiyoshi H, Kouki F, Taisuke O, Masakazu S, Yu FS, Toshihiro O, Masato Y, Kazuo S, Kenji Y. Physicochemical properties and cellular toxicity of nanocrystal quantum dots depend on their surface modification. Nano Lett. 2004;4:2163-9.

16. Mondal MK, Mukherjee S, Joardar N, Roy D, Chowdhury P, Sinha Babu SP. Synthesis of smart graphene quantum dots: a benign biomaterial for prominent intracellular imaging and improvement of drug efficacy. Appl Surf Sci. 2019:495:143562.

17. Sangam S, Gupta A, Shakeel A, Bhattacharya R, Sharma AK, Suhag D, Chakrabarti S, Garg SK, Chattopadhyay S, Basu B, et al. Sustainable synthesis of single crystalline sulphur-doped graphene quantum dots for bioimaging and beyond. Green Chem. 2018;20:4245-59.

18. Fasbender S, Zimmermann L, Cadeddu RP, Luysberg M, Moll B, Janiak C, Heinzel T, Haas R. The low toxicity of graphene quantum dots is reflected by marginal gene expression changes of primary human hematopoietic stem cells. Sci Rep. 2019;9:12028.

19. Li Z, Fan J, Tong C, Zhou H, Wang W, Li B, Liu B, Wang W. A smart drug-delivery nanosystem based on carboxylated graphene quantum dots for tumor-targeted chemotherapy. Nanomedicine (Lond). 2019;14:2011-25.

20. Liang J, Huang Q, Hua C, Hu J, Chen B, Wan J, Hu Z, Wang B. pHresponsive nanoparticles loaded with graphene quantum dots and doxorubicin for intracellular imaging, drug delivery and efficient cancer therapy. ChemistrySelect. 2019;4:6004-122.

21. Wang Y, Xu N, He Y, Wang J, Wang D, Gao Q, Xie S, Li Y, Zhang R, Cai Q. Loading graphene quantum dots into optical-magneto nanoparticles for real-time tracking in vivo. Materials (Basel). 2019;12(12):2191.

22. Sweetman MJ, Hickey SM, Brooks DA, Hayball JD, Plush SE. A practical guide to prepare and synthetically modify graphene quantum dots. Adv Func Mater. 2019;29:1808740.

23. Zhu S, Song $Y$, Wang J, Wan H, Zhang Y, Ning Y, Yang B. Photoluminescence mechanism in graphene quantum dots: quantum confinement effect and surface/edge state. Nano Today. 2017;13:10-4.

24. Shang W, Cai T, Zhang Y, Liu D, Liu S. Facile one pot pyrolysis synthesis of carbon quantum dots and graphene oxide nanomaterials: all carbon hybrids as eco-environmental lubricants for low friction and remarkable wear-resistance. Tribol Int. 2018;118:373-80.

25. Wang S, Zhang K, Wang Q, Fan Y, Shen J, Li L, Yang L, Zhang W. Graphene quantum dot-assisted preparation of water-borne reduced graphene oxide/polyaniline: from composite powder to layer-by-layer self-assembly film and performance enhancement. Electrochim Acta. 2019;295:29-38. 
26. Ying $Y$, He P, Ding G, Peng X. Ultrafast adsorption and selective desorption of aqueous aromatic dyes by graphene sheets modified by graphene quantum dots. Nanotechnology. 2016;27:245703.

27. Luo P, Guan X, Yu Y, Li X, Yan F. Hydrothermal synthesis of graphene quantum dots supported on three-dimensional graphene for supercapacitors. Nanomaterials. 2019;9:201.

28. He J, Li Z, Zhao R, Lu Y, Shi L, Liu J, Dong X, Xi F. Aqueous synthesis of amphiphilic graphene quantum dots and their application as surfactants for preparing of fluorescent polymer microspheres. Colloids Surf A. 2019;563:77-83.

29. Shukla A, Dhanasekaran P, Nagaraju N, Bhat SD, Pillai VK. A facile synthesis of graphene nanoribbon-quantum dot hybrids and their application for composite electrolyte membrane in direct methanol fuel cells. Electrochim Acta. 2019;297:267-80.

30. Li Y, Li S, Wang Y, Wang J, Liu H, Liu X, Wang L, Liu X, Xue W, Ma $\mathrm{N}$. Electrochemical synthesis of phosphorus-doped graphene quantum dots for free radical scavenging. Phys Chem Chem Phys. 2017:19:11631-8

31. Deka MJ, Chowdhury D. CVD assisted hydrophobic graphene quantum dots: fluorescence sensor for aromatic amino acids. ChemistrySelect. 2017;2:1999-2005.

32. Huang K, Lu W, Yu X, Jin C, Yang D. Highly pure and luminescent graphene quantum dots on silicon directly grown by chemical vapor deposition. Part Part Syst Charact. 2016;33:8-14.

33. Lee J, Kim K, Park WI, Kim BH, Park JH, Kim TH, Bong S, Kim CH, Chae $\mathrm{G}$, Jun $\mathrm{M}$, et al. Uniform graphene quantum dots patterned from selfassembled silica nanodots. Nano Lett. 2012;12:6078-83.

34. Kang SH, Mhin S, Han H, Kim KM, Jones JL, Ryu JH, Kang JS, Kim SH, Shim KB. Ultrafast method for selective design of graphene quantum dots with highly efficient blue emission. Sci Rep. 2016;6:38423.

35. Russo P, Liang R, Jabari E, Marzbanrad E, Toyserkani E, Zhou YN. Single-step synthesis of graphene quantum dots by femtosecond laser ablation of graphene oxide dispersions. Nanoscale. 2016;8:8863-77.

36. Santiago SR, Lin TN, Yuan CT, Shen JL, Huang HY, Lin CA. Origin of tunable photoluminescence from graphene quantum dots synthesized via pulsed laser ablation. Phys Chem Chem Phys. 2016;18:22599-605.

37. Calabro RL, Yang DS, Kim DY. Liquid-phase laser ablation synthesis of graphene quantum dots from carbon nano-onions: Comparison with chemical oxidation. J Colloid Interface Sci. 2018;527:132-40.

38. Zhuo S, Shao M, Lee S-T. Upconversion and downconversion fluorescent graphene quantum dots: ultrasonic preparation and photocatalysis. ACS Nano. 2012;6:1059-64.

39. Iannazzo D, Pistone A, Ferro S, De Luca L, Monforte AM, Romeo R, Buemi MR, Pannecouque C. Graphene quantum dots based systems as HIV inhibitors. Bioconjug Chem. 2018;29:3084-93.

40. Gu S, Hsieh C-T, Chiang Y-M, Tzou D-Y, Chen Y-F, Gandomi YA. Optimization of graphene quantum dots by chemical exfoliation from graphite powders and carbon nanotubes. Mater Chem Phys. 2018;215:104-11.

41. Ding H, Zhang F, Zhao C, LVY, Ma G, Wei W, Tian Z. Beyond a carrier: graphene quantum dots as a probe for programmatically monitoring anti-cancer drug delivery, release, and response. ACS Appl Mater Interfaces. 2017:9:27396-401.

42. Wang N, Li L, Zhou N, Chen S. Cage breaking of $\mathrm{C}_{60}$ into photoluminescent graphene oxide quantum dots: an efficient peroxidase mimic. Phys Status Solidi B. 2018;255:1700535.

43. Qian Z, Zhou J, Chen J, Wang C, Chen C, Feng H. Nanosized N-doped graphene oxide with visible fluorescence in water for metal ion sensing. J Mater Chem. 2011;21:17635.

44. Liu F, Sun Y, Zheng Y, Tang N, Li M, Zhong W, Du Y. Gram-scale synthesis of high-purity graphene quantum dots with multicolor photoluminescence. RSC Adv. 2015;5:103428-32.

45. Lu Q, Wu C, Liu D, Wang H, Su W, Li H, Zhang Y, Yao S. A facile and simple method for synthesis of graphene oxide quantum dots from black carbon. Green Chem. 2017;19:900-4.

46. Halder A, Godoy-Gallardo M, Ashley J, Feng X, Zhou T, Hosta-Rigau L, Sun $Y$. One-pot green synthesis of biocompatible graphene quantum dots and their cell uptake studies. ACS Appl Bio Mater. 2018;1:452-61.

47. Liu B, Xie J, Ma H, Zhang X, Pan Y, Lv J, Ge H, Ren N, Su H, Xie X, et al. From graphite to graphene oxide and graphene oxide quantum dots. Small. 2017;13:1601001.
48. Teymourinia $\mathrm{H}$, Salavati-Niasari M, Amiri O, Farangi M. Facile synthesis of graphene quantum dots from corn powder and their application as down conversion effect in quantum dot-dye-sensitized solar cell. J Mol Liq. 2018;251:267-72.

49. Chu X, Dai P, Dong Y, Sun W, Bai L, Zhang W. The acetic acid gas sensing properties of graphene quantum dots (GQDs)-ZnO nanocomposites prepared by hydrothermal method. J Mater Sci: Mater Electron. 2017;28:19164-73.

50. Chu X, Dai P, Liang S, Bhattacharya A, Dong Y, Epifani M. The acetone sensing properties of $\mathrm{ZnFe}_{2} \mathrm{O}_{4}$-graphene quantum dots (GQDs) nanocomposites at room temperature. Phys E. 2019;106:326-33.

51. Mehrdad-Vahdati B, Pourhashem S, Sedghi M, Vaezi Z, Shojaedin-Givi B, Rashidi A, Naderi-Manesh $\mathrm{H}$. A novel aspect of functionalized graphene quantum dots in cytotoxicity studies. Toxicol In Vitro. 2019;61:104649.

52. Wang L, Li W, Wu B, Li Z, Wang S, Liu Y, Pan D, Wu M. Facile synthesis of fluorescent graphene quantum dots from coffee grounds for bioimaging and sensing. Chem Eng J. 2016;300:75-82.

53. Wang $\mathrm{Y}$, Jin $\mathrm{Y}$, Duan $\mathrm{Y}$, Jia $\mathrm{M}$. $\mathrm{Fe}_{3} \mathrm{O}_{4}$ quantum dots on $3 \mathrm{D}$-framed graphene aerogel as an advanced anode material in lithium-ion batteries. Ionics. 2017;23:2005-111.

54. Gao XX, Zhou X, Ma YF, Wang CP, Chu FX. A fluorometric and colorimetric dual-mode sensor based on nitrogen and iron co-doped graphene quantum dots for detection of ferric ions in biological fluids and cellular imaging. New J Chem. 2018;42:14751-6.

55. Mathew MS, Sukumaran K, Joseph K. Graphene carbon dot assisted sustainable synthesis of gold quantum cluster for bio-friendly white light emitting material and ratiometric sensing of mercury $\left(\mathrm{Hg}^{2+}\right)$. ChemistrySelect. 2018;3:9545-54.

56. Wang L, Wu B, Li W, Wang S, Li Z, Li M, Pan D, Wu M. Amphiphilic graphene quantum dots as self-targeted fluorescence probes for cell nucleus imaging. Adv Biosyst. 2018;2:1700191.

57. Huang D, Zeng M, Wang L, Zhang L, Cheng Z. Biomimetic colloidal photonic crystals by coassembly of polystyrene nanoparticles and graphene quantum dots. RSC Adv. 2018;8:34839-47.

58. Pourhashem S, Ghasemy E, Rashidi A, Vaezi MR. Corrosion protection properties of novel epoxy nanocomposite coatings containing silane functionalized graphene quantum dots. J Alloy Compd. 2018;731:1112-8.

59. Oh B, Lee CH. Development of thiolated-graphene quantum dots for regulation of ROS in macrophages. Pharm Res. 2016;33:2736-47.

60. Tian R, Zhong S, Wu J, Jiang W, Shen Y, Jiang W, Wang T. Solvothermal method to prepare graphene quantum dots by hydrogen peroxide. Opt Mater. 2016;60:204-8.

61. Zhang JH, Sun T, Niu A, Tang YM, Deng S, Luo W, Xu Q, Wei D, Pei DS. Perturbation effect of reduced graphene oxide quantum dots (rGOQDs) on aryl hydrocarbon receptor (AhR) pathway in zebrafish. Biomaterials. 2017;133:49-59.

62. Wang Z, Yu J, Zhang X, Li N, Liu B, Li Y, Wang Y, Wang W, Li Y, Zhang L, et al. Large-scale and controllable synthesis of graphene quantum dots from rice husk biomass: a comprehensive utilization strategy. ACS Appl Mater Interfaces. 2016;8:1434-9.

63. Das R, Rajender G, Giri PK. Anomalous fluorescence enhancement and fluorescence quenching of graphene quantum dots by single walled carbon nanotubes. Phys Chem Chem Phys. 2018;20:4527-37.

64. Wang S, Li Z, Xu X, Zhang G, Li Y, Peng Q. Amino-functionalized graphene quantum dots as cathode interlayer for efficient organic solar cells: quantum dot size on interfacial modification ability and photovoltaic performance. Adv Mater Interfaces. 2019;6:1801480.

65. Wang R, Fan H, Jiang W, Ni G, Qu S. Amino-functionalized graphene quantum dots prepared using high-softening point asphalt and their application in Fe3+ detection. Appl Surf Sci. 2019;467-468:446-55.

66. Xu H, Zhou S, Liu J, Wei Y. Nanospace-confined preparation of uniform nitrogen-doped graphene quantum dots for highly selective fluorescence dual-function determination of Fe3+ and ascorbic acid. RSC Adv. 2018;8:5500-8.

67. Luo Y, Li M, Sun L, Xu Y, Hu G, Tang T, Wen J, Li X. Tuning the photoluminescence of graphene quantum dots by co-doping of nitrogen and sulfur. J Nanopart Res. 2017;19:1328.

68. Fang X, Ding J, Yuan N, Sun P, Lv M, Ding G, Zhu C. Graphene quantum dot incorporated perovskite films: passivating grain 
boundaries and facilitating electron extraction. Phys Chem Chem Phys. 2017;19:6057-63.

69. Huang D, Yin L, Lu X, Lin S, Niu Z, Niu J. Directional electron transfer mechanisms with graphene quantum dots as the electron donor for photodecomposition of perfluorooctane sulfonate. Chem Eng J. 2017;323:406-14.

70. Kaur M, Kaur M, Sharma VK. Nitrogen-doped graphene and graphene quantum dots: A review onsynthesis and applications in energy, sensors and environment. Adv Coll Interface Sci. 2018:259:44-64.

71. Gao H, Xue C, Hu G, Zhu K. Production of graphene quantum dots by ultrasound-assisted exfoliation in supercritical $\mathrm{CO}_{2} / \mathrm{H}_{2} \mathrm{O}$ medium. Ultrason Sonochem. 2017:37:120-7.

72. Murugesan B, Sonamuthu J, Pandiyan N, Pandi B, Samayanan S, Mahalingam $S$. Photoluminescent reduced graphene oxide quantum dots from latex of Calotropis gigantea for metal sensing, radical scavenging, cytotoxicity, and bioimaging in Artemia salina: a greener route. J Photochem Photobiol B. 2018;178:371-9.

73. Tang L, Ji R, Cao X, Lin J, Jiang H, Li X, Teng KS, Luk CM, Zeng S, Hao J, Lau SP. Deep ultraviolet photoluminescence of water-soluble selfpassivated graphene quantum dots. ACS Nano. 2012;6:5102-10.

74. Kharangarh PR, Umapathy S, Singh G. Investigation of sulfur related defects in graphene quantum dots for tuning photoluminescence and high quantum yield. Appl Surf Sci. 2018;449:363-70.

75. Chen L, Wu C, Du P, Feng X, Wu P, Cai C. Electrolyzing synthesis of boron-doped graphene quantum dots for fluorescence determination of $\mathrm{Fe}^{3+}$ ions in water samples. Talanta. 2017;164:100-9.

76. Huang H, Yang S, Li Q, Yang Y, Wang G, You X, Mao B, Wang H, Ma Y, He P, et al. Electrochemical cutting in weak aqueous electrolytes: the strategy for efficient and controllable preparation of graphene quantum dots. Langmuir. 2018;34:250-8.

77. Liu D, Chen X, Hu Y, Sun T, Song Z, Zheng Y, Cao Y, Cai Z, Cao M, Peng $L$, et al. Raman enhancement on ultra-clean graphene quantum dots produced by quasi-equilibrium plasma-enhanced chemical vapor deposition. Nat Commun. 2018:9:193.

78. Lin TN, Chih KH, Yuan CT, Shen JL, Lin CA, Liu WR. Laser-ablation production of graphene oxide nanostructures: from ribbons to quantum dots. Nanoscale. 2015;7:2708-15.

79. Sajjad M, Makarov V, Sultan MS, Jadwisienczak WM, Weiner BR, Morell G. Synthesis, optical, and magnetic properties of graphene quantum dots and iron oxide nanocomposites. Adv Mater Sci Eng. 2018:2018:1-8.

80. Shang NG, Papakonstantinou P, Sharma S, Lubarsky G, Li M, McNeill DW, Quinn AJ, Zhou W, Blackley R. Controllable selective exfoliation of highquality graphene nanosheets and nanodots by ionic liquid assisted grinding. Chem Commun. 1877;2012:48.

81. Sun X, Luo D, Liu J, Evans D. Monodisperse chemically modified graphene obtained by density gradient ultracentrifugal rate separation. ACS Nano. 2010;4:3381-9.

82. Lin L, Zhang S. Creating high yield water soluble luminescent graphene quantum dots via exfoliating and disintegrating carbon nanotubes and graphite flakes. Chem Commun. 2012;48:10177-9.

83. Alidad F, Navik R, Gai Y, Zhao Y. Production of pristine graphene quantum dots from graphite by a shear-mixer in supercritical $\mathrm{CO}_{2}$. Chem Phys Lett. 2018;710:64-9.

84. Sapkota B, Benabbas A, Lin HG, Liang W, Champion P, Wanunu M. Peptide-decorated tunable-fluorescence graphene quantum dots. ACS Appl Mater Interfaces. 2017;9:9378-87.

85. Kundu S, Yadav RM, Narayanan TN, Shelke MV, Vajtai R, Ajayan PM, Pillai VK. Synthesis of N, F and S co-doped graphene quantum dots. Nanoscale. 2015;7:11515-9.

86. Hu C, Su T-R, Lin T-J, Chang C-W, Tung K-L. Yellowish and blue luminescent graphene oxide quantum dots prepared via a microwave-assisted hydrothermal route using $\mathrm{H}_{2} \mathrm{O}_{2}$ and $\mathrm{KMnO}_{4}$ as oxidizing agents. New J Chem. 2018:42:3999-4007.

87. Li W, Li M, Liu Y, Pan D, Li Z, Wang L, Wu M. Three-minute ultra-rapid microwave-assisted synthesis of bright fluorescent graphene quantum dots for live cell staining and white LEDs. ACS Appl Nano Mater. 2018;1:1623-30.

88. Wang K, Dong J, Sun L, Chen H, Wang Y, Wang C, Dong L. Effects of elemental doping on the photoluminescence properties of graphene quantum dots. RSC Adv. 2016;6:91225-32.
89. Naik JP, Sutradhar P, Saha M. Molecular scale rapid synthesis of graphene quantum dots (GQDs). J Nanostruct Chem. 2017;7:85-9.

90. Allahbakhsh A, Bahramian AR. Self-assembly of graphene quantum dots into hydrogels and cryogels: Dynamic light scattering, UV-Vis spectroscopy and structural investigations. J Mol Liq. 2018;265:172-80.

91. Tian P, Tang L, Teng KS, Lau SP. Graphene quantum dots from chemistry to applications. Mater Today Chem. 2018;10:221-58.

92. Ponomarenko LA, Schedin F, Katsnelson MI, Yang R, Hill EW, Novosetov KS, Geim AK. Chaotic dirac billiard in graphene quantum dots. Science. 2008:320:356-8.

93. Guo Z, Cai B, Cao Q, Su Y, Li M, Hu J, Yang Z, Zhang Y. Facile synthesis of amine-functionalized graphene quantum dots with highly $\mathrm{pH}$-sensitive photoluminescence. Fullerenes Nanotubes Carbon Nanostruct. 2017;25:704-9.

94. Huang D, Zhou H, Wu Y, Wang T, Sun L, Gao P, Sun Y, Huang H, Zhou G, $\mathrm{Hu}$ J. Bottom-up synthesis and structural design strategy for graphene quantum dots with tunable emission to the near infrared region. Carbon. 2019:142:673-84

95. Ou J, Tao Y, Xue J, Kong Y, Dai J, Deng L. Electrochemical enantiorecognition of tryptophan enantiomers based on graphene quantum dotschitosan composite film. Electrochem Commun. 2015;57:5-9.

96. Hasanpour F, Nekoeinia M, Semnani A, Shojaei S. $\mathrm{NiMnO}_{3}$ nanoparticles anchored on graphene quantum dot: application in sensitive electroanalysis of dobutamine. Microchem J. 2018;142:17-23.

97. Ramezanzadeh B, Karimi B, Ramezanzadeh M, Rostami M. Synthesis and characterization of polyaniline tailored graphene oxide quantum dot as an advance and highly crystalline carbon-based luminescent nanomaterial for fabrication of an effective anti-corrosion epoxy system on mild steel. J Taiwan Inst Chem Eng. 2019;95:369-82.

98. Luo Y, Wang Y, Yan H, Wu Y, Zhu C, Du D, Lin Y. SWCNTs@GQDs composites as nanocarriers for enzyme-free dual-signal amplification electrochemical immunoassay of cancer biomarker. Anal Chim Acta. 2018:1042:44-51.

99. Ko NR, Nafiujjaman M, Lee JS, Lim HN. Lee Yk, Kwon IK: Graphene quantum dot-based theranostic agents for active targeting of breast cancer. RSC Adv. 2017:7:11420-7.

100. Liu B, Peng L, Chen W, Wang J, Han T, Mo Q. Preparation and luminescent properties of controllable graphene quantum dot. Nanosci Nanotechnol Lett. 2017;9:297-300

101. Liu R, Wu D, Feng X, Mullen K. Bottom-up fabrication of photoluminescent graphene quantum dots with uniform morphology. J Am Chem Soc. 2011:133:15221-3.

102. Luo Y, Li M, Sun L, Xu Y, Li M, Hu G, Tang T, Wen J, Li X, Zhang J, Wang L. High fluorescent sulfur regulating graphene quantum dots with tunable photoluminescence properties. J Colloid Interface Sci. 2018:529:205-13.

103. Bian S, Shen C, Qian Y, Liu J, Xi F, Dong X. Facile synthesis of sulfurdoped graphene quantum dots as fluorescent sensing probes for $\mathrm{Ag}^{+}$ ions detection. Sens Actuators B Chem. 2017:242:231-7.

104. Wang G, Guo Q, Chen D, Liu Z, Zheng X, Xu A, Yang S, Ding G. Facile and highly effective synthesis of controllable lattice sulfur-doped graphene quantum dots via hydrothermal treatment of durian. ACS Appl Mater Interfaces. 2018:10:5750-9.

105. Bayat A, Saievar-Iranizad E. Graphene quantum dots decorated rutile $\mathrm{TiO}_{2}$ nanoflowers for water splitting application. J Energy Chem. 2018;27:306-10.

106. Tam TV, Choi WM. One-pot synthesis of highly fluorescent amino-functionalized graphene quantum dots for effective detection of copper ions. Curr Appl Phys. 2018;18:1255-60.

107. Hou X, Li Y, Zhao C. Microwave-assisted synthesis of nitrogen-doped multi-layer graphene quantum dots with oxygen-rich functional groups. Aust J Chem. 2016;69:357.

108. Alves AK, Frantz ACS, Berutti FA. Microwave-assisted oleothermal synthesis of graphene- $\mathrm{TiO}_{2}$ quantum dots for photoelectrochemical oxygen evolution reaction. FlatChem. 2018;12:26-34.

109. Fresco-Cala B, Soriano ML, Sciortino A, Cannas M, Messina F, Cardenas S. One-pot synthesis of graphene quantum dots and simultaneous nanostructured self-assembly via a novel microwave-assisted method: impact on triazine removal and efficiency monitoring. RSC Adv. 2018;8:29939-46. 
110. Zhang C, Cui Y, Song L, Liu X, Hu Z. Microwave assisted one-pot synthesis of graphene quantum dots as highly sensitive fluorescent probes for detection of iron ions and pH value. Talanta. 2016;150:54-60.

111. Campbell E, Hasan MT, Gonzalez Rodriguez R, Akkaraju GR, Naumov AV. Doped graphene quantum dots for intracellular multicolor imaging and cancer detection. ACS Biomater Sci Eng. 2019;5:4671-82.

112. Shen C, Ge S, Pang Y, Xi F, Liu J, Dong X, Chen P. Facile and scalable preparation of highly luminescent N, S co-doped graphene quantum dots and their application for parallel detection of multiple metal ions. J Mater Chem B. 2017;5:6593-600

113. Dong Y, Shao J, Chen C, Li H, Wang R, Chi Y, Lin X, Chen G. Blue luminescent graphene quantum dots and graphene oxide prepared by tuning the carbonization degree of citric acid. Carbon. 2012;50:4738-43.

114. Zhou L, Geng J, Liu B. Graphene quantum dots from polycyclic aromatic hydrocarbon for bioimaging and sensing of $\mathrm{Fe}^{3+}$ and hydrogen peroxide. Part Part Syst Charact. 2013;30:1086-92.

115. Ju J, Chen W. Synthesis of highly fluorescent nitrogen-doped graphene quantum dots for sensitive, label-free detection of Fe (III) in aqueous media. Biosens Bioelectron. 2014;58:219-25.

116. Bayat A, Saievar-Iranizad E. Synthesis of green-photoluminescent single layer graphene quantum dots: determination of $\mathrm{HOMO}$ and LUMO energy states. J Lumin. 2017;192:180-3.

117. Teymourinia H, Salavati-Niasari M, Amiri O, Safardoust-Hojaghan H. Synthesis of graphene quantum dots from corn powder and their application in reduce charge recombination and increase free charge carriers. J Mol Liq. 2017;242:447-55.

118. Shehab M, Ebrahim S, Soliman M. Graphene quantum dots prepared from glucose as optical sensor for glucose. J Lumin. 2017;184:110-6.

119. Dey T, Mukherjee S, Ghorai A, Das S, Ray SK. Surface state selective tunable emission of graphene quantum dots exhibiting novel therma quenching characteristics. Carbon. 2018:140:394-403.

120. Hasan MT, Gonzalez-Rodriguez R, Ryan C, Faerber N, Coffer JL, Naumov AV. Photo-and electroluminescence from nitrogen-doped and nitrogen-sulfur codoped graphene quantum dots. Adv Func Mater. 2018:28:1804337.

121. Mishra P, Bhat BR. Synthesis and characterization of graphene quantum dots and their size reduction using swift heavy ion beam. Radiat Eff Defects Solids. 2018;173:232-8.

122. Wang L, Li W, Wu B, Li Z, Pan D, Wu M. Room-temperature synthesis of graphene quantum dots via electron-beam irradiation and their application in cell imaging. Chem Eng J. 2017;309:374-80.

123. Xu Y, Hu X, Guan P, Du C, Tian Y, Ding S, Li Z, Yan C. A novel controllable molecularly imprinted drug delivery system based on the photothermal effect of graphene oxide quantum dots. J Mater Sci. 2019;54:9124-39.

124. Nene LC, Managa M, Nyokong T. Photo-physicochemical properties and in vitro photodynamic therapy activity of morpholine-substituted Zinc(II)-Phthalocyanines $\pi-\pi$ stacked on biotinylated graphene quantum dots. Dyes Pigm. 2019;165:488-98

125. Yue J, He L, Tang Y, Yang L, Wu B, Ni J. Facile design and development of photoluminescent graphene quantum dots grafted dextran/ glycol-polymeric hydrogel for thermoresponsive triggered delivery of buprenorphine on pain management in tissue implantation. J Photochem Photobiol B. 2019;197:111530.

126. Ghafary SM, Nikkhah M, Hatamie S, Hosseinkhani S. Simultaneous Gene Delivery And Tracking Through Preparation Of Photo-Luminescent Nanoparticles Based On Graphene Quantum Dots And Chimeric Peptides. Sci Rep. 2017;7:9552.

127. Havanur S, Batish I, Cheruku SP, Gourishetti K. P EJ, Kumar N: Poly(N, $\mathrm{N}$-diethyl acrylamide)/functionalized graphene quantum dots hydrogels loaded with doxorubicin as a nano-drug carrier for metastatic lung cancer in mice. Mater Sci Eng, C. 2019;105:110094.

128. Ju J, Chen W. Graphene quantum dots as fluorescence probes for sensing metal ions: synthesis and applications. Curr Org Chem. 2015;19:1150-62.

129. Fan L, Hu Y, Wang X, Zhang L, Li F, Han D, Li Z, Zhang Q, Wang Z, Niu L. Fluorescence resonance energy transfer quenching at the surface of graphene quantum dots for ultrasensitive detection of TNT. Talanta. 2012;101:192-7

130. Ju J, Chen W. In situ growth of surfactant-free gold nanoparticles on nitrogen-doped graphene quantum dots for electrochemical detection of hydrogen peroxide in biological environments. Anal Chem. 2015;87:1903-10.

131. Li Y, Zhang W, Zhang L, Li J, Su Z, Wei G. Sequence-designed peptide nanofibers bridged conjugation of graphene quantum dots with graphene oxide for high performance electrochemical hydrogen peroxide biosensor. Adv Mater Interfaces. 2017;4:1600895.

132. Soleymani J, Hasanzadeh M, Somi MH, Ozkan SA, Jouyban A. Targeting and sensing of some cancer cells using folate bioreceptor functionalized nitrogen-doped graphene quantum dots. Int J Biol Macromol. 2018;118:1021-34.

133. Yang Y, Liu Q, Liu Y, Cui J, Liu H, Wang P, Li Y, Chen L, Zhao Z, Dong Y. A novel label-free electrochemical immunosensor based on functionalized nitrogen-doped graphene quantum dots for carcinoembryonic antigen detection. Biosens Bioelectron. 2017;90:31-8.

134. Landry MP, Ando H, Chen AY, Cao J, Kottadiel VI, Chio L, Yang D, Dong J, Lu TK, Strano MS. Single-molecule detection of protein efflux from microorganisms using fluorescent single-walled carbon nanotube sensor arrays. Nat Nanotechnol. 2017;12:368-77.

135. Song H, Wang Y, Wang J, Wang G, He J, Wei H, Luo S. Preparation and biodistribution of ${ }^{131}$ |-labeled graphene quantum dots. J Radioanal Nucl Chem. 2018;316:685-90.

136. Rajender G, Goswami U, Giri PK. Solvent dependent synthesis of edge-controlled graphene quantum dots with high photoluminescence quantum yield and their application in confocal imaging of cancer cells. J Colloid Interface Sci. 2019;541:387-98.

137. Zhang Q, Deng S, Liu J, Zhong X, He J, Chen X, Feng B, Chen Y, Ostrikov K. Cancer-targeting graphene quantum dots: fluorescence quantum yields, stability, and cell selectivity. Adv Func Mater. 2019;29:1805860.

138. Wang L, Wu B, Li W, Li Z, Zhan J, Geng B, Wang S, Pan D, Wu M. Industrial production of ultra-stable sulfonated graphene quantum dots for Golgi apparatus imaging. J Mater Chem B. 2017;5:5355-61.

139. Kundu S, Sarojinijeeva P, Karthick R, Anantharaj G, Saritha G, Bera R, Anandan S, Patra A, Ragupathy P, Selvaraj M, et al. Enhancing the efficiency of DSSCs by the modification of $\mathrm{TiO}_{2}$ photoanodes using $\mathrm{N}, \mathrm{F}$ and S-codoped graphene quantum dots. Electrochim Acta. 2017;242:337-43

140. Pan D, Zhang J, Li Z, Wu M. Hydrothermal route for cutting graphene sheets into blue-luminescent graphene quantum dots. Adv Mater. 2010;22:734-8.

141. Yao X, Niu X, Ma K, Huang P, Grothe J, Kaskel S, Zhu Y. Graphene Quantum dots-capped magnetic mesoporous silica nanoparticles as a multifunctional platform for controlled drug delivery, magnetic hyperthermia, and photothermal therapy. Small. 2017;13:1602225.

142. Chung S, Revia RA, Zhang M. Graphene quantum dots and their applications in bioimaging, biosensing, and therapy. Adv Mater. 2019. e1904362.

143. Alegret N, Criado A, Prato M. Recent advances of graphene-based hybrids with magnetic nanoparticles for biomedical applications. Curr Top Med Chem. 2017;24:529-36.

144. Justin R, Tao K, Román S, Chen D, Xu Y, Geng X, Ross IM, Grant RT, Pearson A, Zhou G, et al. Photoluminescent and superparamagnetic reduced graphene oxide-iron oxide quantum dots for dualmodality imaging, drug delivery and photothermal therapy. Carbon. 2016:97:54-70

145. Kuo WS, Chen HH, Chen SY, Chang CY, Chen PC, Hou YI, Shao YT, Kao $\mathrm{HF}$, Lilian Hsu CL, Chen YC, et al. Graphene quantum dots with nitrogen-doped content dependence for highly efficient dual-modality photodynamic antimicrobial therapy and bioimaging. Biomaterials. 2017;120:185-94

146. Guo M, Xiang HJ, Wang Y, Zhang QL, An L, Yang SP, Ma Y, Wang Y, Liu $J G$. Ruthenium nitrosyl functionalized graphene quantum dots as an efficient nanoplatform for NIR-light-controlled and mitochondria-targeted delivery of nitric oxide combined with photothermal therapy. Chem Commun. 2017;53:3253-6.

147. Xuan Y, Zhang RY, Zhang XS, An J, Cheng K, Li C, Hou XL, Zhao YD. Targeting $\mathrm{N}$-doped graphene quantum dot with high photothermal conversion efficiency for dual-mode imaging and therapy in vitro. Nanotechnology. 2018;29:355101.

148. Fang J, Liu Y, Chen Y, Ouyang D, Yang G, Yu T. Graphene quantum dots-gated hollow mesoporous carbon nanoplatform for targeting 
drug delivery and synergistic chemo-photothermal therapy. Int J Nanomed. 2018;13:5991-6007.

149. Sun H, Gao N, Dong K, Ren J, Qu X. Graphene quantum dots-bandaids used for wound disinfection. ACS Nano. 2014;8:6202-10.

150. Biswas A, Khandelwal P, Das R, Salunke G, Alam A, Ghorai S, Chattopadhyay S, Poddar P. Oxidant mediated one-step complete conversion of multi-walled carbon nanotubes to graphene quantum dots and their bioactivity against mammalian and bacterial cells. J Mater Chem B. 2017:5:785-96.

151. Luo Y, Li M, Hu G, Tang T, Wen J, Li X, Wang L. Enhanced photocatalytic activity of sulfur-doped graphene quantum dots decorated with $\mathrm{TiO}_{2}$ nanocomposites. Mater Res Bull. 2018;97:428-35.

152. Ahmed B, Kumar S, Ojha AK, Hirsch F, Riese S, Fischer I. Facile synthesis and photophysics of graphene quantum dots. J Photochem Photobiol, A. 2018;364:671-8.

153. Wu C, Chen R, Ma C, Cheng R, Gao X, Wang T, Liu Y, Huo P, Yan Y. Construction of upconversion nitrogen doped graphene quantum dots modified BiVO4 photocatalyst with enhanced visible-light photocatalytic activity. Ceram Int. 2019;45:2088-96.

154. Sun L, Luo Y, Li M, Hu G, Xu Y, Tang T, Wen J, Li X, Wang L. Role of Pyridinic-N for Nitrogen-doped graphene quantum dots in oxygen reaction reduction. J Colloid Interface Sci. 2017;508:154-8.

155. Sajjadi S, Khataee A, Kamali M. Sonocatalytic degradation of methylene blue by a novel graphene quantum dots anchored CdSe nanocatalyst. Ultrason Sonochem. 2017;39:676-85.

156. Xu T, Wang D, Dong L, Shen H, Lu W, Chen W. Graphitic carbon nitride co-modified by zinc phthalocyanine and graphene quantum dots for the efficient photocatalytic degradation of refractory contaminants. Appl Catal B. 2019;244:96-106.

157. Wang C, Jin J, Sun Y, Yao J, Zhao G, Liu Y. In-situ synthesis and ultrasound enhanced adsorption properties of $\mathrm{MoS}_{2}$ /graphene quantum dot nanocomposite. Chem Eng J. 2017;327:774-82.

158. Yao Y, Guo Y, Du W, Tong X, Zhang X. In situ synthesis of sulfur-doped graphene quantum dots decorated carbon nanoparticles hybrid as metal-free electrocatalyst for oxygen reduction reaction. J Mater Sci Mater Electron. 2018;29:17695-705.

159. Riaz R, Ali M, Anwer $H$, Ko MJ, Jeong SH. Highly porous self-assembly of nitrogen-doped graphene quantum dots over reduced graphene sheets for photo-electrocatalytic electrode. J Colloid Interface Sci. 2019:557:174-84.

160. Majumder T, Dhar S, Chakraborty P, Debnath K, Mondal SP. Advantages of $\mathrm{ZnO}$ nanotaper photoanodes in photoelectrochemical cells and graphene quantum dot sensitized solar cell applications. $J$ Electroanal Chem. 2018:813:92-101.

161. Huang Y, Lin L, Shi T, Cheng S, Zhong Y, Chen C, Tang Z. Graphene quantum dots-induced morphological changes in $\mathrm{CuCO}_{2} \mathrm{~S}_{4}$ nanocomposites for supercapacitor electrodes with enhanced performance. Appl Surf Sci. 2019;463:498-503

162. Qian J, Shen C, Yan J, Xi F, Dong X, Liu J. Tailoring the electronic properties of graphene quantum dots by $P$ doping and their enhanced performance in metal-free composite photocatalyst. J Phys Chem C. 2018;122:349-58

163. Liu T, Yu K, Gao L, Chen H, Wang N, Hao L, Li T, He H, Guo Z. A graphene quantum dot decorated SrRuO3mesoporous film as an efficient counter electrode for high-performance dye-sensitized solar cells. J Mater Chem A. 2017;5:17848-55.

164. Gao F, Liu F, Bai X, Xu X, Kong W, Liu J, Lv F, Long L, Yang Y, Li M. Tuning the photoluminescence of graphene oxide quantum dots by photochemical fluorination. Carbon. 2019;141:331-8.

165. Lu J, Yeo PS, Gan CK, Wu P, Loh KP. Transforming $C_{60}$ molecules into graphene quantum dots. Nat Nanotechnol. 2011;6:247-52.

166. Vatanparast M, Shariatinia Z. AIN and AIP doped graphene quantum dots as novel drug delivery systems for 5-fluorouracil drug: Theoretical studies.J Fluorine Chem. 2018:211:81-93.

167. Vatanparast M, Shariatinia Z. Computational studies on the doped graphene quantum dots as potential carriers in drug delivery systems for isoniazid drug. Struct Chem. 2018;29:1427-48.

168. Zhou M, Shen Q, Shen JW, Jin L, Zhang L, Sun Q, Hu Q, Liang L. Understanding the size effect of graphene quantum dots on protein adsorption. Colloids Surf, B. 2019;174:575-81.
169. Vatanparast M, Shariatinia Z. Revealing the role of different nitrogen functionalities in the drug delivery performance of graphene quantum dots: a combined density functional theory and molecular dynamics approach. J Mater Chem B. 2019;7:6156-71.

170. Bayoumy AM, Refaat A, Yahia IS, Zahran HY, Elhaes H, Ibrahim MA, Shkir M. Functionalization of graphene quantum dots (GQDs) with chitosan biopolymer for biophysical applications. Opt Quantum Electron. 2019;52:16.

171. Xue Z, Sun Q, Zhang L, Kang Z, Liang L, Wang Q, Shen JW. Graphene quantum dot assisted translocation of drugs into a cell membrane. Nanoscale. 2019;11:4503-14.

172. Qian C, Yan P, Wan G, Liang S, Dong Y, Wang J. Facile synthetic Photoluminescent Graphene Quantum dots encapsulated $\beta$-cyclodextrin drug carrier system for the management of macular degeneration: Detailed analytical and biological investigations. J Photochem Photobiol, B. 2018;189:244-9.

173. Masoudipour E, Kashanian S. 3,4, Maleki N: A targeted drug delivery system based on dopamine functionalized nano graphene oxide. Chem Phys Lett. 2017;688:56-63.

174. De S, Patra K, Ghosh D, Dutta K, Dey A, Sarkar G, Maiti J, Basu A, Rana D, Chattopadhyay D. Tailoring the efficacy of multifunctional biopolymeric graphene oxide quantum dot-based nanomaterial as nanocargo in cancer therapeutic application. ACS Biomater Sci Eng. 2018;4:514-31.

175. Liu R, Zhao J, Huang Z, Zhang L, Zou M, Shi B, Zhao S. Nitrogen and phosphorus co-doped graphene quantum dots as a nano-sensor for highly sensitive and selective imaging detection of nitrite in live cell. Sens Actuators B Chem. 2017;240:604-12.

176. Kellici S, Acord J, Power NP, Morgan DJ, Coppo P, Heil T, Saha B. Rapid synthesis of graphene quantum dots using a continuous hydrothermal flow synthesis approach. RSC Adv. 2017;7:14716-20.

177. Li K, Liu W, Ni Y, Li D, Lin D, Su Z, Wei G. Technical synthesis and biomedical applications of graphene quantum dots. J Mater Chem B. 2017;5:4811-26.

178. Jegannathan P, Termeh Yousefi A, Karim MSA, Kadri NA. Enhancement of graphene quantum dots based applications via optimum physical chemistry: a review. Biocybern Biomed Eng. 2018:38:481-97.

179. Pardo J, Peng Z, Leblanc RM. Cancer targeting and drug delivery using carbon-based quantum dots and nanotubes. Molecules. 2018;23:378.

180. Chong Y, Ma Y, Shen H, Tu X, Zhou X, Xu J, Dai J, Fan S, Zhang Z. The in vitro and in vivo toxicity of graphene quantum dots. Biomaterials. 2014;35:5041-8.

181. Henna TK, Pramod K. Graphene quantum dots redefine nanobiomedicine. Mater Sci Eng C Mater Biol Appl. 2020;110:110651.

182. Kim D, Yoo JM, Hwang H, Lee J, Lee SH, Yun SP, Park MJ, Lee M, Choi S, Kwon SH, et al. Graphene quantum dots prevent a-synucleinopathy in Parkinson's disease. Nat Nanotechnol. 2018:13:812-8.

183. Khlebtsov N, Dykman L. Biodistribution and toxicity of engineered gold nanoparticles: a review of in vitro and in vivo studies. Chem Soc Rev. 2011:40:1647-71.

184. Khodadadei F, Safarian S, Ghanbari N. Methotrexate-loaded nitrogendoped graphene quantum dots nanocarriers as an efficient anticancer drug delivery system. Mater Sci Eng, C. 2017;79:280-5.

185. Ju J, Regmi S, Fu A, Lim S, Liu Q. Graphene quantum dot based charge-reversal nanomaterial for nucleus-targeted drug delivery and efficiency controllable photodynamic therapy. J Biophotonics. 2019;12:e201800367.

186. Dong J, Wang K, Sun L, Sun B, Yang M, Chen H, Wang Y, Sun J, Dong L. Application of graphene quantum dots for simultaneous fluorescence imaging and tumor-targeted drug delivery. Sens Actuators B Chem. 2018;256:616-23.

187. Sung SY, Su YL, Cheng W, Hu PF, Chiang CS, Chen WT, Hu SH. Graphene quantum dots-mediated theranostic penetrative delivery of drug and photolytics in deep tumors by targeted biomimetic nanosponges. Nano Lett. 2019:19:69-81.

188. Gao Y, Zhong S, Xu L, He S, Dou Y, Zhao S, Chen P, Cui X. Mesoporous silica nanoparticles capped with graphene quantum dots as multifunctional drug carriers for photo-thermal and redox-responsive release. Microporous Mesoporous Mater. 2019;278:130-7.

189. Wei Z, Yin X, Cai Y, Xu W, Song C, Wang Y, Zhang J, Kang A, Wang Z, Han $W$. Antitumor effect of a Pt-loaded nanocomposite based on graphene 
quantum dots combats hypoxia-induced chemoresistance of oral squamous cell carcinoma. Int J Nanomed. 2018;13:1505-24.

190. Jia Q, Li Z, Guo C, Huang X, Song Y, Zhou N, Wang M, Zhang Z, He L, Du M. A Y-cyclodextrin-based metal-organic framework embedded with graphene quantum dots and modified with PEGMA via SI-ATRP for anticancer drug delivery and therapy. Nanoscale. 2019;11:20956-67.

191. Iannazzo D, Pistone A, Salamo M, Galvagno S, Romeo R, Giofre SV, Branca C, Visalli G, Di Pietro A. Graphene quantum dots for cancer targeted drug delivery. Int J Pharm. 2017:518:185-92.

192. Iannazzo D, Pistone A, Celesti C, Triolo C, Patane S, Giofre SV, Romeo R, Ziccarelli I, Mancuso R, Gabriele B, et al. A Smart nanovector for cancer targeted drug delivery based on graphene quantum dots. Nanomaterials. 2019:9:282.

193. Qin Y, Zhou S. Graphene quantum dots-based drug delivery for ovarian cancer therapy. Drug Metab Rev. 2016;48:62-3.

194. Wang X, Sun X, Lao J, He H, Cheng T, Wang M, Wang S, Huang F. Multifunctional graphene quantum dots for simultaneous targeted cellular imaging and drug delivery. Colloids Surf B. 2014;122:638-44.

195. Nigam Joshi P, Agawane S, Athalye MC, Jadhav V, Sarkar D, Prakash R. Multifunctional inulin tethered silver-graphene quantum dots nanotheranostic module for pancreatic cancer therapy. Mater Sci Eng, C. 2017:78:1203-11.

196. Su Y, Yu T, Chiang W, Chiu H, Chang C, Chiang C, Hu S. Hierarchically targeted and penetrated delivery of drugs to tumors by size-changeable graphene quantum dot nanoaircrafts for photolytic therapy. Adv Func Mater. 2017;27:1700056.

197. Choi SY, Baek SH, Chang SJ, Song Y, Rafique R, Lee KT, Park TJ. Synthesis of upconversion nanoparticles conjugated with graphene oxide quantum dots and their use against cancer cell imaging and photodynamic therapy. Biosens Bioelectron. 2017;93:267-73.
198. Liu X, Shou D, Chen C, Mao H, Kong Y, Tao Y. Core-shell structured polypyrrole/mesoporous $\mathrm{SiO}_{2}$ nanocomposite capped with graphene quantum dots as gatekeeper for irradiation-controlled release of methotrexate. Mater Sci Eng C. 2017:81:206-12.

199. Javanbakht S, Nazari N, Rakhshaei R, Namazi H. Cu-crosslinked carboxymethylcellulose/naproxen/graphene quantum dot nanocomposite hydrogel beads for naproxen oral delivery. Carbohydr Polym. 2018;195:453-9.

200. Javanbakht S, Shaabani A. Encapsulation of graphene quantum dotcrosslinked chitosan by carboxymethylcellulose hydrogel beads as a pH-responsive bio-nanocomposite for the oral delivery agent. Int J Biol Macromol. 2019;123:389-97.

201. Justin R, Chen B. Multifunctional chitosan-magnetic graphene quantum dot nanocomposites for the release of therapeutics from detachable and non-detachable biodegradable microneedle arrays. Interface Focus. 2018:8:20170055.

202. Xiao S, Zhou D, Luan P, Gu B, Feng L, Fan S, Liao W, Fang W, Yang L, Tao E, et al. Graphene quantum dots conjugated neuroprotective peptide improve learning and memory capability. Biomaterials. 2016;106:98-110

203. Du J, Feng B, Dong Y, Zhao M, Yang X. Vanadium coordination compounds loaded on graphene quantum dots (GQDs) exhibit improved pharmaceutical properties and enhanced anti-diabetic effects. Nanoscale. 2020;12:9219-30.

\section{Publisher's Note}

Springer Nature remains neutral with regard to jurisdictional claims in published maps and institutional affiliations.
Ready to submit your research? Choose BMC and benefit from:

- fast, convenient online submission

- thorough peer review by experienced researchers in your field

- rapid publication on acceptance

- support for research data, including large and complex data types

- gold Open Access which fosters wider collaboration and increased citations

- maximum visibility for your research: over 100M website views per year

At BMC, research is always in progress.

Learn more biomedcentral.com/submissions 